CME

\title{
Venous Thromboembolic Events in the Rehabilitation Setting
}

\author{
Brian M. Kelly, DO, Brian M. Yoder, MD, ${ }^{\dagger}$ Chi-Tsai Tang, MD, \\ Thomas W. Wakefield, MD
}

\begin{abstract}
Venous thromboembolism (VTE) is a disease entity that encompasses both deep venous thrombosis and pulmonary embolism. During the past decade there have been significant advances in the understanding of prophylaxis and treatment of VTE. There is an extensive research base from which conclusions can be drawn, but the heterogeneity within the rehabilitation patient population makes the development of rigid VTE protocols challenging and overwhelming for the busy clinician. Given the prevalence of this condition and its associated morbidity and mortality, we review the evidence for the prevention, identification, and optimal treatment of VTE in the rehabilitation population. Our goal is to highlight studies that have the most clinical applicability for the care of VTE patients from a physiatrist's perspective. At times, information about acute care protocols is included in our discussion because these situations are encountered during the consultation process that identifies patients for rehabilitation needs.
\end{abstract}

PM R 2010;2:647-663

\section{INTRODUCTION}

Venous thromboembolism (VTE) is a disease that encompasses both deep venous thrombosis (DVT) and pulmonary embolism (PE). VTEs are an important source of morbidity and mortality in acute and chronic rehabilitation populations. For example, despite adequate anticoagulant prophylaxis (ACP) and the use of a sequential compression device (SCD) when ACP was contra indicated, 40 cases of symptomatic DVTs and 9 PEs were diagnosed in the 492 inpatients admitted to our 32-bed academic acute rehabilitation unit during a period of 1 year. These incidence numbers do not include asymptomatic VTEs, VTEs diagnosed before the acute rehabilitation admission, or VTEs diagnosed after discharge. As such, the VTE rate was 10\%, of which $8 \%$ were DVTs and 2\% were PEs. Similar incidence rates have been found within other large inpatient rehabilitation settings [1-5]. Limited data exist regarding the economic burden of VTE. Published estimates suggest that the direct cost of VTE approaches $\$ 3$ to $\$ 4$ billion annually. These estimates do not reflect the additional indirect cost of lost workdays and productivity that often accompany a VTE diagnosis $[6,7]$.

\section{NATURAL HISTORY OF VTE}

\section{Frequency}

The incidence of detected and undetected VTE varies widely on the basis of the population being studied and the method of diagnosis being used. Treatment of VTE is critical. Clinical PE occurs in $26 \%$ to $67 \%$ of untreated proximal DVTs and is associated with an $11 \%$ to $23 \%$ rate of mortality. If treated, these numbers reduce to $5 \%$ and $1 \%$, respectively [8].

\section{Risk Factors}

Some medical conditions are consistently associated with VTE across the studies, specifically, recent hospitalization, recent surgery or trauma, active malignancy, and immobilization. These conditions are now considered established risk factors for VTE [9]. VTE may be
B.M.K. Department of Physical Medicine and Rehabilitation, University of Michigan Health System, 325 Eisenhower, Suite 200, Ann Arbor, Ml 48108. Address correspondence to: B.M.K.; e-mail: brikelly@med.umich.edu Disclosure: nothing to disclose

B.M.Y. University Physician Group and Department of Physical Medicine and Rehabilitation, Rehabilitation Institute of Michigan, Detroit, MI

Disclosure: nothing to disclose

C.-T.T. Physical Medicine and Rehabilitation, Washington University Orthopedics, St. Louis, MO

Disclosure: nothing to disclose

T.W.W. Department of Surgery, University of Michigan Health System, Ann Arbor, MI Disclosure: nothing to disclose

Disclosure Key can be found on the Table of Contents and at www.pmrjournal.org

Submitted for publication December 2, 2009; accepted March 14, 2010.

${ }^{\dagger}$ Deceased. 
classified as (1) associated with temporary risk factors (surgery, trauma, immobilization), (2) associated with persistent risk factors (cancer, paralysis), or (3) unprovoked. These associations are of particular importance in rehabilitation patients, whom often have several risk factors, as outlined in Table 1 [10-14]. Idiopathic or "unprovoked" is a VTE in the absence of any identifiable temporary or persistent risk factors for thrombosis, which can account for $26 \%$ of first-time cases [15].

Table 1. Venous thrombotic events: risk factors

\begin{tabular}{|c|c|}
\hline $\begin{array}{l}\text { Apparent/Acquired Risk } \\
\text { Factors }\end{array}$ & $\begin{array}{c}\text { Occult/Genetic Risk } \\
\text { Factors }\end{array}$ \\
\hline Acute infectious disease & Antithrombin deficiency \\
\hline Acute medical illness & Blood Group A \\
\hline Acute spinal cord injury & Factor V Leiden mutation \\
\hline $\begin{array}{l}\text { Cancer therapy (hormonal, } \\
\text { chemotherapy, radiotherapy) }\end{array}$ & $\begin{array}{l}\text { High levels of clotting } \\
\text { factor }\end{array}$ \\
\hline Central venous access & Hyperhomocysteinemia \\
\hline Congestive heart failure & Lupus anticoagulant \\
\hline $\begin{array}{l}\text { Estrogen containing oral } \\
\text { contraceptives }\end{array}$ & $\begin{array}{l}\text { Methylene tetrahydrofolate } \\
\text { reductase (if homo- }\end{array}$ \\
\hline Family history of VTE & cysteine is elevated) \\
\hline Heart or respiratory failure & Protein C deficiency \\
\hline Hemiparesis & Protein S deficiency \\
\hline $\begin{array}{l}\text { Heparin induced } \\
\text { thrombocytopenia }\end{array}$ & $\begin{array}{l}\text { Prothrombin 20210A gene } \\
\text { mutation }\end{array}$ \\
\hline $\begin{array}{l}\text { Hormone replacement therapy } \\
\text { Immobility/bed confinement }\end{array}$ & $\begin{array}{l}\text { Undiagnosed apparent/ } \\
\text { acquired factors }\end{array}$ \\
\hline $\begin{array}{l}>12 \text { hours } \\
\text { - Plaster cast } \\
\text { - Hospitalization }\end{array}$ & \\
\hline Increasing age* & \\
\hline Inflammatory bowel disease & \\
\hline Malignancy & \\
\hline Myeloproliferative disorders & \\
\hline Myocardial Infarction & \\
\hline Nephrotic syndrome & \\
\hline $\begin{array}{l}\text { Neurosurgery Intracranial > } \\
\text { extracranial }\end{array}$ & \\
\hline Obesity & \\
\hline $\begin{array}{l}\text { Paroxysmal nocturnal } \\
\text { hemoglobinuria }\end{array}$ & \\
\hline $\begin{array}{l}\text { Pregnancy: }>3 \text { past } \\
\text { pregnancies, and postpartum } \\
\text { period }\end{array}$ & \\
\hline $\begin{array}{l}\text { Race: African-American }>\text { white } \\
>\text { Latino }>\text { Asian }\end{array}$ & \\
\hline $\begin{array}{l}\text { Selective estrogen receptor } \\
\text { modulators }\end{array}$ & \\
\hline $\begin{array}{l}\text { Sex: } F>M \text { before menopause, } \\
M>F \text { afterwards }\end{array}$ & \\
\hline Surgery & \\
\hline $\begin{array}{l}\text { Thrombophilia (inherited or } \\
\text { acquired) }\end{array}$ & \\
\hline Trauma & \\
\hline $\begin{array}{l}\text { Varicose veins/venous } \\
\text { insufficiency }\end{array}$ & \\
\hline VTE history & \\
\hline
\end{tabular}

VTE $=$ venous thromboembolism.

*Grows exponentially starting in the fifth decade of life.

\section{The Onset of DVT and Propagation}

The timing of DVT onset varies greatly. DVTs may develop intraoperatively upon induction of anesthesia or weeks later [13]. After onset, many DVTs resolve spontaneously and remain undiagnosed, whereas others may propagate and become symptomatic. DVT propagation is most common in the first week, but risk continues for at least the first month. Up to $20 \%$ to $50 \%$ of distal DVTs propagate proximally if left untreated and result in PEs in 26\% to 67\% of cases [16-20]. Treatment lowers the risk of proximal propagation to $7 \%$ to $30 \%[21]$.

\section{DVT Resolution and Rethrombosis}

A venous thrombus will decrease in mass over time, but remnants of the clot will remain because of incomplete resorption. Recannulization of totally occluded vessels, when it occurs, takes place over years [20]. Rethrombosis is common in patients with DVTs, especially when left untreated. Rethrombosis occurs in 29\% to $47 \%$ of untreated patients and in $4.7 \%$ to $30.3 \%$ of treated patients. There is a greater risk of rethrombosis in patients with ongoing risk factors [22-26]. In general, the incidence of rethrombosis decreases over time but is greatest between 6 and 12 months and continues to at least 10 years $[23,25,27,28]$.

\section{Upper Extremity DVTs}

Upper extremity DVTs comprise approximately $1 \%$ to $4 \%$ of all episodes [29]. Upper extremity DVTs can be classified as primary or secondary. The primary form can be idiopathic or related to exertion (Page-Schroetter syndrome). Exertionrelated upper extremity DVTs may be related to abnormal anatomy and often follow strenuous activity [30]. The secondary form of upper extremity DVTs are more common than the primary form and risk factors include hypercoagulable states, cancer, pacemakers, and subclavian or intrajugular lines [12].

\section{VTE COMPLICATIONS}

\section{Pulmonary Emboli}

PEs are the most frequent and severe sequela of DVTs. The embolus obstructs a pulmonary artery and results in the hemodynamic effects of increased workload on the right ventricle, increased alveolar dead space, bronchoconstriction, arterial hypoxemia secondary to cardiac output decline, ventilation perfusion mismatch, and right-to-left shunt $[28,31]$. Massive PEs usually occur without warning, and it is often difficult to resuscitate patients. Up to $10 \%$ to $30 \%$ of massive PEs are lethal depending on the patient's cardiopulmonary status. Most acute symptoms in patients who survive typically resolve over the course of 2 weeks when treated [32]. 
However, patients who survive an acute $\mathrm{PE}$ are at high risk for recurrent PE [31].

\section{Postthrombotic Syndrome}

Postthrombotic syndrome (PTS) is the most common cause of VTE morbidity. The cause of PTS is destruction of venous valves, which results in venous reflux, venous hypertension, and edema. PTS is characterized initially by dull pain when standing, cramping, pruritus, venous ectasia, edema, stasis changes, hyperpigmentation, lipodermatosclerosis, indurated cellulitis, and venous ulcers. Within 2 years of their diagnosis, $27 \%$ to $47 \%$ of patients with a history of DVT develop PTS, of which approximately 10\% are associated with ulceration $[33,34]$. Proximal and recurrent DVTs are far more likely to be associated with an increased frequency and severity of PTS $[19,35,36]$. Those patients who develop PTS have worsening quality of life at 4 months with a predicted $10 \%$ decrease in the ability to work and a $5 \%$ increase in substantial life stress [37]. The cost of treating PTS is roughly $75 \%$ of the cost of treating the initial DVT $[38,39]$.

The use of graded compression stockings (GCS) will reduce the incidence of PTS, even if the DVT is proximal, by approximately $37 \%$ to $70 \%[33,34,40,41]$. Ambulation during the acute stage of DVT also reduces the risk of PTS [38,42]. The use of 30 to $40 \mathrm{mmHg}$ calf-high compression stockings for 2 years after DVT development will help reduce the risk of PTS $[36,40]$. Severe and intractable PTS can be improved with long-term use of an intermittent compression extremity pump, but most insurance carriers in the United States do not pay for its use for PTS $[38,41]$.

\section{VTE CONFIRMATION}

\section{DVT Evaluation}

Signs and Symptoms. The signs and symptoms of DVT include calf swelling, tenderness, pitting edema, dilated superficial veins, fever, and erythema [43,33]. However, these are not always reliable [44]. In light of these inconsistencies, protocols involving the use of clinical estimation tools that include both the history and physical examination to better direct further testing have been developed. The most notable of these tools is the Wells clinical prediction rule, outlined in Table $2[43,44]$.

In the acute inpatient rehabilitation patient population, it would be extremely rare for any patient to have a score of 0 . In addition, many of the variables of Wells criteria may be unobtainable or difficult to judge secondary to aphasia, hemiparesis, and casting. These factors, which are common to our patient population, may limit the usefulness of such a tool.

$D$-dimer. D-dimer is a degradation product of a crosslinked fibrin blood clot. Levels of D-dimer typically are
Table 2. Wells simplified clinical model for DVT assessment

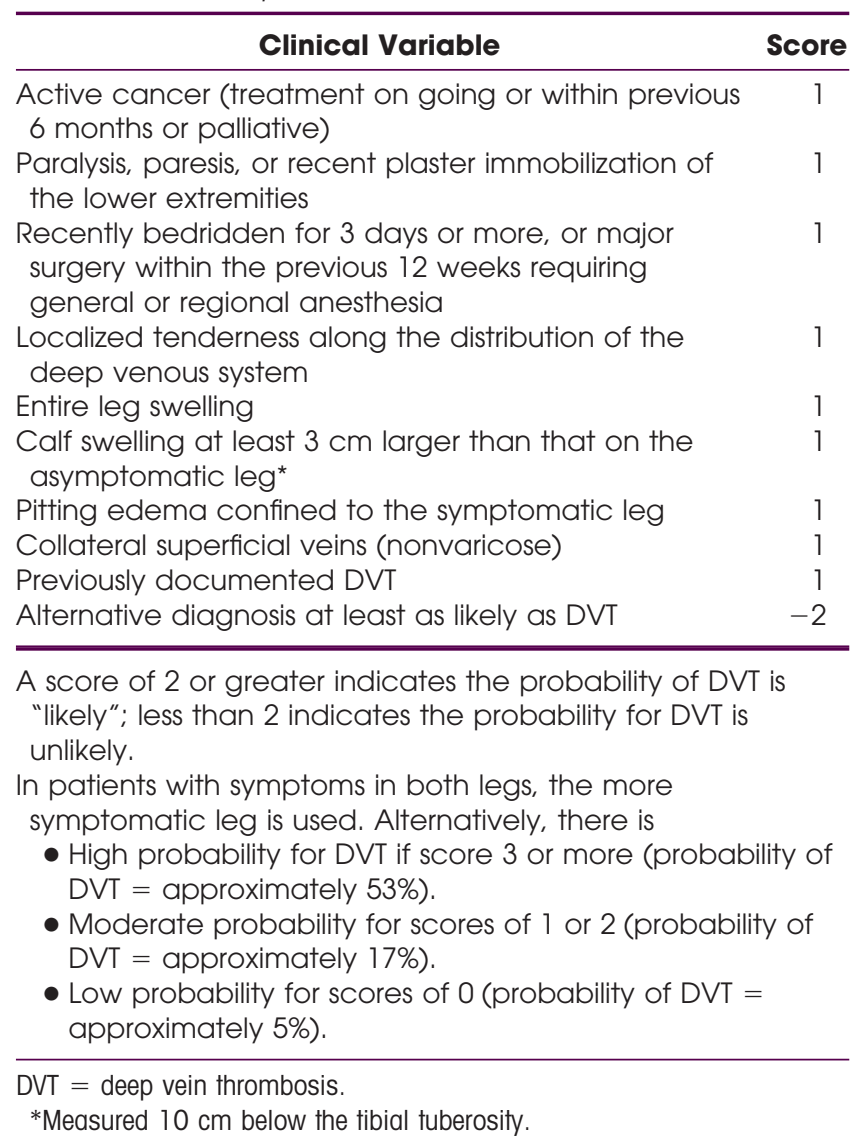

increased in patients with acute VTE. Many physiological and pathological conditions can increase plasma D-dimer levels (eg, pregnancy, age, trauma, cancer, inflammation, and several other clinical conditions). D-dimer levels have also been demonstrated to increase with age, and some advocate that D-dimer should not be performed in patients older than 80 years old [45-47]. However, D-dimer levels may fail to increase in patients with acute VTE for multiple reasons (impaired fibrinolytic activity, use of heparin or oral anticoagulants, onset of symptoms more than 2 weeks before blood sampling). For these reasons, D-dimer testing has a high sensitivity but a low specificity in the diagnosis of acute VTE $[48,49]$. A positive D-dimer result is not useful to "rule in" the diagnosis of VTE; rather, the potential value for a negative test is to "rule out" the diagnosis.

D-dimer levels can be measured by rapid enzyme-linked immunosorbent assay (ELISA) and by quantitative and qualitative latex assays. These tests are all available for individual use in emergency conditions and are reported to have almost $100 \%$ sensitivity and $100 \%$ negative predictive value for diagnosing DVT [50,51]. Research indicates that latex D-dimer assays are slightly less sensitive than ELISA methods, but latex techniques are more practical because of time, cost, and simplicity. These tests are performed in almost all laboratories, and results can be obtained in 15 minutes. 
In patients presenting with suspected DVT, a diagnostic strategy with the use of D-dimer testing and clinical judgment to select patients for venous Doppler ultrasound (DUS) is safe and feasible. The addition of D-dimer testing to the diagnostic algorithm has the potential to make the diagnosis of DVT in outpatients more convenient and economical. In patients who are considered clinically unlikely to have DVT (on the basis of Wells clinical prediction rule; Table 2) and who have a negative D-dimer test, the diagnosis of DVT can safely be excluded without the need for further DUS [52]. D-dimers have been studied in the rehabilitation population and determined to be a reliable adjunct method for excluding DVT [53]. The D-dimer should not be used as a screening test. It should only be used if the physician is convinced that DVT is a diagnostic possibility. Indiscriminant use of the D-dimer as a screening test will result in many unnecessary DUS tests.

Venous Ultrasound. Although contrast venography is still considered the criterion standard for identifying DVT, this test is expensive, time-consuming, invasive, painful, and has low repeatability [54]. Recently, DUS has emerged as the diagnostic imaging study of choice. Compared with venography, this method is less time-consuming, less expensive, has greater repeatability, and has the added benefits of being noninvasive and nonpainful [54-56]. In addition, advances in imaging technology have improved the sensitivity and accuracy of DUS $[55,56]$. Despite these advantages, serial workup of suspected DVT cases with DUS is not practical or economically viable $[57,58]$. The use of the D-dimer can help identify which patients need DUS. First, the negative Ddimer result in patients who were clinically unlikely to have a DVT eliminates the need for DUS completely. Second, for patients that are clinically likely to have a DVT, DUS can be limited to patients with a positive $\mathrm{D}$-dimer result and prevent overutilization [52].

\section{PE Evaluation}

Signs and Symptoms. The need to diagnose PE rapidly and accurately is of greater importance than for DVT given the acute risk of mortality. Because PEs are a consequence of DVTs, ruling out a DVT provides value in excluding PE and alternately, ruling in a DVT assists in diagnosing PE. Consequently, a DVT evaluation and its associated diagnostic tests is a part of many PE diagnostic algorithms. Like DVT, clinical signs and symptoms of PE are both insensitive and nonspecific. To increase clinical accuracy in diagnosing PE, Wells developed a clinical estimation tool for establishing a patient's risk of PE on the basis of clinical signs and symptoms that is summarized in Table 3 [59-63]. Once again, it would be rare for an acute inpatient rehabilitation patient to have a score of less than 2 and be in the low probability category.

Imaging Studies. In addition to the DUS, clinical assessment tools, and D-dimer assays used in diagnosing DVT,
Table 3. Wells simplified clinical model for assessment of PE

\begin{tabular}{lc}
\hline \multicolumn{1}{c}{ Clinical Variables } & Points \\
\hline Clinical signs and symptoms of DVT & 3 \\
- minimum of leg swelling and pain with & \\
palpation of the deep veins & 3 \\
An alternative diagnosis is less likely than PE & 1.5 \\
Heart rate faster than 100 beats/min & 1.5 \\
Immobilization or surgery in the previous 4 weeks & 1.5 \\
Previous DVT/PE & 1 \\
Hemoptysis & 1 \\
Malignancy(current, treated in the last 6 months, & \\
or palliative) &
\end{tabular}

High probability for $\mathrm{PE}$ if score $>6.0$ (probability of $\mathrm{PE}=$ approximately 66\%).

Moderate probability for PE if score is $2.0-6.0$ (probability of $\mathrm{PE}=$ approximately $20 \%$ ).

Low probability for $\mathrm{PE}$ if score $<2.0$ (probability of $\mathrm{PE}=$ approximately $2 \%$ ).

$\mathrm{DVT}=$ deep vein thrombosis; $\mathrm{PE}=$ pulmonary embolism.

there are several imaging tests unique to PE work-up. These tests are ventilation and perfusion scans, spiral computed tomography (CT), and pulmonary angiography. Spiral CTs have gained acceptance for the diagnosis of PE during the last decade and have been shown to be superior to ventilation and perfusion scan for detection and exclusion of PE [64]. They are safer and more available than pulmonary angiogram. It is important to correlate the patient's presentation with the CT scan. If the data are concordant, then the CT scan can be used alone to make clinical decisions. If the results of the clinical evaluation and the CT scan are discordant, then additional testing is indicated [65].

Laboratory Studies. Arterial blood gases are often ordered during a PE work-up. Although arterial blood gases provide useful information on the patient's overall respiratory status, they are of relatively little value in making the diagnosis [66]. As is the case in the work-up for DVT, a negative D-dimer can be helpful in excluding PE in some instances $[36,60,61]$. However, a negative D-dimer with rapid ELISA does not exclude PE in more than 15\% of patients with a high probability clinical assessment [67].

\section{VTES BY REHABILITATION DIAGNOSIS}

\section{Spinal Cord Injury}

Without VTE prophylaxis, patients with acute spinal cord injury (SCI) have the greatest incidence of DVT among all hospital groups. One study [68] showed $6.5 \%$ of SCI patients have DVT on admission screening to acute rehabilitation. Data from the SCI Model centers show that 9.8\% of patients develop DVT during inpatient acute rehabilitation [2]. The incidence of VTE has been reported as high as 47\% to 100\% in the first year among subjects enrolled within 72 hours of injury $[69,70]$. The greatest period of risk is during the first 2 
weeks after the injury, with the frequency decreasing thereafter [69]. Most patients with SCI who develop DVT do not have clinical signs or symptoms such as swelling, warmth, or pain; therefore, physicians must be extra vigilant.

The high incidence of VTE in SCI patients is related to stasis, intimal injury, and hypercoagulability, which are all sequelae of acute neurologic impairment. Stasis will result from peripheral venous dilation, compounded by a reduction of blood flow to paralyzed muscle and loss of the gastrocnemius-soleus pump [71]. The neurologic injury leads to changes in the coagulation cascade and results in hypercoagulability. Additional coagulation change involves factor VIII and is a result of endothelial damage and blood stasis [72]. There is a measurable increase in collagen-induced platelet aggregation compared with healthy adults. This increase is observed 12 to 48 weeks after trauma in several studies [73,74].

Approximately $2.6 \%$ of SCI patients develop PE during acute rehabilitation [2]. According to the SCI Model System Database, PEs account for $10 \%$ of the overall mortality in the first postinjury year and are the leading cause of sudden death [2,75]. VTEs in SCI patients have lower rates of recanalization and therefore require longer treatment times, resulting in an associated high risk of bleeding. A retrospective cohort study of 16,240 SCI patients identifies the following risk factors: male gender, African-American race, tracheostomy placement, and lower extremity trauma. Risk increases exponentially with age [76]

Low-molecular-weight heparin (LMWH) has been found to be superior to unfractionated heparin (UFH) for VTE prophylaxis in SCI patients $[77,78]$. DVT prophylaxis guidelines after SCI have been developed by the Consortium for Spinal Cord Medicine and are outlined in Table $4[79,80]$. In light of paralysis and collagen-induced platelet aggregation level being increased for greater than 12 weeks and detected up to 48 weeks after injury, coupled with shorter lengths of stay (affecting motor complete with additional risk factors), the risk/benefit ratio for additional prophylaxis time may need to be considered in some patients.

For SCI, all patients should receive some form of thromboprophylaxis. LMWH should be started as soon as hemostasis is achieved, in some cases 24 to 72 hours after injury $[77,80]$. The use of long-term, full-dose anticoagulation with a vitamin-K antagonist (VKA) should be delayed in the first week after injury because of the unpredictable response to dosing with these agents [81]. The American College of Chest Physicians guidelines do not separate motor incomplete in their recommendations but are strong in their recommendation that low-dose UFH (LDUFH), GCS, or an inferior vena cava filter (IVCF) should never be used as solitary prophylactic methods [81]. VTE prophylaxis with LMWH or a VKA should be continued through acute rehabilitation [78]. The authors of prospective studies have not addressed the value of DUS screening in asymptomatic patients, but admission ultrasound screening may be reasonable for patients in whom VTE prophylaxis is delayed greater than 72 hours (patient ultimately transferred to level I center, hemorrhage) [79,82]. A recent analysis is not able to support or reject routine screening, whereas other authors believe that screening should be routine regardless of American Spinal Injury Association level or cause of the patient's injury $[83,84]$. A retrospective study of 369 SCI patients found admission screening to be cost effective and able to detect DVT in 9.4\% of cases [68].

Placement of IVCF has been inconsistently used as a method of PE prophylaxis without diagnosed VTE. This practice is not optimal because IVCFs are associated with an increased rate of recurrent DVT (4-fold), consistent with previous work by Decousus et al [24] and Gorman et al [85]. In cervical SCI, an additional risk of the placement of an IVCF has been identified. In a series of 13 patients with tetraplegia who had the original Greenfield IVCFs placed, 4 of 11 follow-up abdominal radiographs, taken in a mean of 75 weeks after insertion, revealed caudal migration of the filters [86]. It is suggested that the use of assisted cough techniques (quad coughing) potentially caused the migration of the filters in these cases. Furthermore, placement of an IVCF does not offer added protection against PE, which is the primary reason for the procedure [85].

\section{Trauma}

Without proper VTE prophylaxis, patients with multitrauma or major trauma have a DVT risk exceeding 50\%, of which $18 \%$ are proximal [77]. A study of mixed-trauma patients found VTE rates of $27 \%$ total and $7 \%$ proximal despite SCD prophylaxis [87]. VTEs are the third most frequent cause of

Table 4. Guidelines for prevention of VTE in SCl patients

\begin{tabular}{|c|c|c|c|}
\hline & Motor Incomplete & Motor Complete & $\begin{array}{l}\text { Motor Complete With Other } \\
\text { Risk Factors* }\end{array}$ \\
\hline Method of prophylaxis & CS/CB and UFH 5000 units TID ${ }^{\dagger}$ & $\begin{array}{l}\text { CS/CB and UFH adjusted to } \\
\text { aPTT or LMWH }\end{array}$ & $\begin{array}{l}\text { CS/CB and UFH adjusted to aPTT } \\
\text { or LMWH and consider IVCF }\end{array}$ \\
\hline Duration of prophylaxis & $\begin{array}{l}\text { CS/CB } 2 \text { weeks; UFH while in } \\
\text { hospital for ASIA D or up to } 8 \\
\text { weeks for ASIA C }\end{array}$ & $\begin{array}{l}\text { CS/CB } 2 \text { weeks; UFH or } \\
\text { LMWH at least } 8 \text { weeks }\end{array}$ & $\begin{array}{l}\text { CS/CB } 2 \text { weeks; UFH or LMWH for } \\
12 \text { weeks or while in hospital }\end{array}$ \\
\hline
\end{tabular}

aPTT = activated partial thromboplastin time; ASIA = American Spinal Injury Association; CS/CB = compression stockings/compression boots.; IVCF = inferior vena cava filter; $\mathrm{LMWH}=$ low-molecular-weight heparin; $\mathrm{SCI}=$ spinal cord injury; $\mathrm{TID}=3$ times daily; UFH = unfractionated heparin; VTE = venous thromboembolism.

*Lower limb fracture, previous thrombosis, cancer, heart failure, obesity, age $>70 \mathrm{y}$.

†Updated dosing [80]. 
in-hospital mortality with a rate of $18 \%$ to $43 \%$ for trauma patients [88-90]. SCI, lower extremity and pelvic fractures, lower extremity burns, major venous repair, the use of femoral lines, prolonged immobility, and delay in ACP are independent VTE risk factors, which are more common in these patients [89]. DVT diagnosis in trauma patients can be challenging because venous ultrasound and physical evaluation can be limited by edema, bandages, casts, and patient cooperation.

Despite the high risk of VTE, there have been few randomized trials for trauma patients [77,90-93]. Trauma patients are often at very high risk for bleeding, and consequently, VTE prophylaxis with mechanical prophylaxis (MP) as monotherapy is common. There are no randomized controlled trials of MP in general trauma patients, but in a retrospective analysis of trauma patients receiving SCD monotherapy, there is a relative risk increase of 1.5 for PE relative to ACP $[77,87,94]$. The subcutaneous administration of LDUFH is commonly used in trauma patients. After the use of LMWH became common, it was compared with LDUFH. A randomized, double-blind trial revealed a proximal DVT rate of $15 \%$ with LDUFH compared with $6 \%$ with LMWH [77]. LMWH is significantly more efficacious for thromboprophylaxis, and LDUFH should not be used as monotherapy in trauma patients $[77,95]$.

The authors of a prospective randomized controlled study of trauma patients with multiple fractures and no central nervous system injury compared different protocols of LMWH and venous foot pump prophylaxis. In one group, only enoxaparin, a LMWH, was started within 24 to 48 hours of injury and in the other group, a venous foot pump was used as monotherapy and started immediately. The addition of enoxaparin prophylaxis as a second agent was added 5 days later [92]. The authors found the patients in the foot pump-enoxaparin group had fewer large DVTs and PEs relative to the enoxaparin-only group. This study suggests a benefit to adding MP to any ACP for trauma patients and eases concern about delaying initiation of ACP several days in trauma patients with a high risk of bleeding. Furthermore, the cost of the venous foot pump is covered by the savings of 5 days of chemical prophylaxis [92].

It is recommended that VTE prophylaxis continue throughout the hospital stay, including rehabilitation for major trauma patients [32]. DUS upon admission is recommended in patients with SCI, lower extremity or pelvic fractures, major head injuries, those with in-dwelling femoral lines, and those who have received suboptimal or no prophylaxis [32]. Routine screening of high-risk trauma patients for asymptomatic DVT with the use of DUS is not feasible, nor is it an effective strategy to prevent clinically important VTE. At least $25 \%$ of trauma patients have inadequate ultrasound studies of the deep venous system because of local injuries or poor patient cooperation [95-97]. Furthermore, there is evidence that screening provides no incremental gain in patient protection over the early use of appropriate thromboprophylaxis [95-97].

Again, IVCFs are not recommended as a method of primary VTE prophylaxis $[98,99]$. No randomized trials have studied the prophylactic use of IVCF in any patient population, and we are not aware of evidence that their use is of additional benefit when added to the most effective thromboprophylaxis modality appropriate for the clinical status [100]. There is no direct evidence that prophylactic IVCF insertion would benefit trauma patients or prevent any deaths [101]. Furthermore, IVCF use is associated with both short-term and long-term complications and may result in inappropriate delays in the use of effective thromboprophylaxis [102]. Contrary to recent trends, the availability of retrievable IVCF should not expand the indications for filter insertion [103]. The average time for filter insertion is 6 days after injury, well beyond the high-risk period for bleeding in most patients [104]. Furthermore, the majority of retrievable IVCFs are never removed [103,105]. IVCF insertion is indicated for patients with proven proximal DVT, an absolute contraindication to full-dose anticoagulation, a complication of anticoagulation, or failure of anticoagulation. Even with an IVCF, therapeutic anticoagulation should commence as soon as the contraindication resolves.

\section{Burns}

These patients are at increased risk for VTE events because of a hypercoagulable state, prolonged bed rest, surgical procedures, catheter insertion, and possible septic events [106]. It is recommended to start LDUFH or LMWH as soon as considered safe in patients with one additional risk factor, such as advanced age, morbid obesity, extensive or lower extremity burns, concomitant lower extremity trauma, use of femoral venous catheter, and/or prolonged immobility $[32,36,106,107]$. There are no prospective randomized controlled studies evaluating the effectiveness of any prophylactic preventive measures against DVT in burn patients $[32,106]$. Burn patients commonly exhibit signs of hypercoagulability that puts them at risk for VTE complications. After analysis of more than 3000 burned patients for VTE events, a complication rate of 3.38\% for all VTE related deaths was documented. Despite the hypercoagulable status of burn patients, thrombotic complication and related mortality continue to have a low impact in this population, and most patients receive LDUFH until mobility is sufficient as a mainstay of prophylaxis [108].

\section{Cancer}

Patients with cancer have at least a 6-fold increased risk of VTE, and active cancer accounts for almost $20 \%$ of all new VTE events $[9,10,32,109]$. Furthermore, VTE is one of the most common and costly complications found in cancer patients $[10,110]$. Once VTE develops in a cancer patient, the 
recurrence rate is high, both after and during traditional anticoagulation [111]. The development of VTE in cancer patients is associated with a significant reduction in survival $[109,112,113]$. The risk of VTE varies by cancer type and extent and is especially high among patients with malignant brain tumors; adenocarcinomas of the lung, ovary, pancreas, colon, stomach, prostate, and kidney; and hematologic malignancies [113-117]. Cancer is also an independent predictor of thromboprophylaxis failure (ie, development of postoperative DVT despite the use of thromboprophylaxis) $[111,118]$. In a multicenter, prospective study of $2373 \mathrm{pa}-$ tients who underwent cancer surgery, VTE was the most common cause of 30-day mortality, even though thromboprophylaxis was used in $82 \%$ of patients $[56,118]$

Cancer patients that undergo surgery have twice the risk of postoperative DVT and 3 times the risk of fatal PE [10]. There are many reasons for this increased risk. Surgery in cancer patients is often more extensive (particularly in lower abdominal and pelvic surgery) and often involves venous trauma. Cancer patients undergoing surgical procedures should receive prophylaxis that is appropriate for their current risk state. It should continue for at least 4 to 5 weeks after surgery to reduce the risk of DVT by $62 \%[119,120]$. Patients with cancer have prothrombotic hemostasis, usually are undergoing either chemotherapy or radiation, and often have indwelling central vein catheters, which can trigger thrombosis. Many cancer patients also have prolonged periods of immobilization, which is an independent risk factor for thromboembolism [121]. Cytotoxic, immunosuppressive, and tamoxifen therapies increase VTE risk [115]. Thromboprophylaxis is also indicated in selected palliative care patients to prevent further reduction in their quality of life [122].

Anticoagulation should be initiated in any cancer patient in whom there is a serious consideration of VTE while the diagnostic evaluation is ongoing. Therapeutic options for initial anticoagulation include weight-adjusted UFH, LMWH, or fondaparinux. In most instances, LMWH therapy is preferred, given that it is recommended for long-term therapy of VTE in patients with cancer and facilitates the transition to outpatient management $[123,124]$. In addition, LMWH and fondaparinux are associated with a lower incidence of heparin-induced thrombocytopenia than UFH [125]. When treating VTEs, LMWH is recommended over UFH and warfarin for both acute and long-term treatment of DVT because of better safety and efficacy $[36,124]$. Anticoagulant therapy should continue indefinitely or until the cancer is resolved [36]. LMWH should be used cautiously in patients with significant renal insufficiency (creatinine clearance $<30$ $\mathrm{mL} / \mathrm{min}$ ), and the use of fondaparinux should be avoided in these patients [123].

Indwelling central venous catheters increase the risk of clinically relevant upper extremity deep vein thrombosis by 3- to 4-fold, but prophylaxis should not be given on the basis solely of the presence of these catheters $[32,126]$. Most patients improve with anticoagulation with the catheter left in place [127]. Catheter removal should only be considered in patients whose symptoms fail to resolve with anticoagulation [127]. Clinicians should not use fixed-dose warfarin to prevent thrombosis formation with the indwelling catheters [32]. In the absence of a central venous catheter and the presence of a DVT, anatomic factors contributing to venous occlusion should be investigated. For example, extrinsic compression of the superior vena cava, subclavian, or axillary veins as a result of tumors or nodal metastases should be investigated. Therapy directed at the source of anatomic compression is most effective and endovascular stenting in combination with antineoplastic therapy and anticoagulation has a high rate of success [128].

Cancer patients also have an increased risk of recurrent DVT, particularly in the first month after treatment is discontinued. In a prospective cohort study of 1050 general and cancer patients diagnosed and treated for DVT, recurrent VTE was 4 times more likely in cancer patients with a cumulative incidence of $20 \%$ within 1 year [129]. In patients with cancer and acute VTE, LMWH was more effective than an oral anticoagulant in reducing the risk of recurrent thromboembolism without increasing the risk of bleeding $[124,130,131]$.

\section{Hip/Knee/Spine Surgery}

Major orthopedic surgery is associated with twice the risk of VTE as general surgery. In a study of 310 total patients that underwent total hip arthroplasty (THA), total knee arthroplasty, and hip fracture surgery and who were receiving LMWH prophylaxis, 27\% developed suspected DVT, 12\% had confirmed distal DVT, and $2 \%$ had a confirmed proximal DVT on routine screening $[13,132]$. However, for knee arthroscopy, the risk of DVT development is low [133]. Risk factors specifically linked to patients undergoing orthopedic surgery are obesity, poor American Society of Anesthesiologists physical status classification, and pelvic malignancy [134,135].

Significantly elevated VTE risk continues for 31 to 60 days after total hip replacement, and most symptomatic DVTs occur after discharge [13]. VTEs are the most common cause for readmission to the hospital after THA [81]. DVTs are more prevalent on the operative side but can occur on the contralateral side. DVTs in patients undergoing THA and total knee arthroplasty are more frequently proximal than in other patient populations, likely because of localized trauma to the proximal veins [12]. Extended VTE prophylaxis to 31 days reduces the risk of developing both symptomatic DVTs and PEs by more than $50 \%$ with an increased risk of minor but not major bleeding [19]. For VTE prophylaxis in patients undergoing orthopedic surgery, LMWH is more effective than UFH, and fondaparinux is more effective than LMWH [136-139]. 
Table 5. VTE prophylaxis for orthopedic surgery patients

\begin{tabular}{|c|c|c|}
\hline Elective knee arthroplasty & $\begin{array}{l}\text { LMWH at high-risk dose*, fondaparinux, or } \\
\text { a VKA with the INR 2.0-3.0. }\end{array}$ & $\begin{array}{l}\text { Aspirin, UFH, and MP alone are not recommended. } \\
\text { Duration of therapy should be at least } 10 \text { days. }\end{array}$ \\
\hline Hip fracture surgery & $\begin{array}{l}\text { LMWH at high-risk dose*, Fondaparinux, or } \\
\text { VKA with INR 2.0-3.0. If surgery will be } \\
\text { delayed, then start either UFH or LMWH } \\
\text { after admission and before surgery. }\end{array}$ & $\begin{array}{l}\text { Aspirin alone is not recommended. MP } \\
\text { recommended if ACP is contraindicated because } \\
\text { of high risk of bleeding. Duration of therapy } \\
\text { should be at least } 10 \text { days, but } 28-35 \text { days is } \\
\text { recommended. }\end{array}$ \\
\hline Elective spine surgery & $\begin{array}{l}\text { Early mobilization for patients with no } \\
\text { additional risk factors. For patients with a } \\
\text { risk factor, UFH, } \mathrm{LMWH}^{+} \text {, or perioperative } \\
\text { MP are recommended. In patients with } \\
\text { multiple risk factors, UFH or LMWH in } \\
\text { addition to MP is recommended. }\end{array}$ & $\begin{array}{l}\text { Risk factors include neurologic deficits or } \\
\text { prolonged immobility, advanced age, known } \\
\text { malignancy, previous VTE, anterior surgical } \\
\text { approach. }\end{array}$ \\
\hline
\end{tabular}

UFH dose $=5000$ units SQ BID or TID.

Fondaparinux dose $=2.5 \mathrm{mg} \mathrm{SQ}$ once daily.

$\mathrm{ACP}=$ acute prophylaxis; BID = twice daily; INR = international normalized ratio; LMWH = low-molecular-weight heparin; MP = mechanical prophylaxis; $\mathrm{SQ}=$ subcutaneously; TID $=3$ times daily; UFH $=$ unfractionated heparin; VKA $=$ vitamin $\mathrm{K}$ agonist; $\mathrm{VTE}=$ venous thromboembolism.

$*$ LMWH high-risk dose $=$ enoxaparin $30 \mathrm{mg} \mathrm{SQ}$ q12 or dalteparin 5000 units $\mathrm{SQ}$ once daily.

${ }^{\dagger} \mathrm{LMWH}$ dose = enoxaparin $40 \mathrm{mg} \mathrm{SQ}$ once daily or dalteparin 5000 units SQ once daily.

With elective spine surgery, ACP recommendations are less definitive. Although the incidence of VTE in these patients appears to be considerably lower than that after major lower extremity surgery, some patients may have risk factors such as increased age, previous VTE, anterior surgical approach (involves manipulation of vessels), malignancy, neurologic deficit, a prolonged procedure, and reduced preoperative and postoperative mobility. In these cases, it is recommended that postoperative LDUFH, LMWH, or at least GCS with SCDs be used. Further research is needed to define the appropriate time to initiate postoperative chemical prophylaxis [140]. For all others, frequent and early ambulation is strongly recommended and encouraged $[32,140]$. Guidelines for VTE prophylaxis of selected orthopedic surgery patient populations are listed in Table 5.

\section{Amputees}

Patients undergoing vascular-related amputation have a significant decrease in mobility and tend to be older than traumatic amputees. Postsurgical swelling, dressings, and tenderness decrease the specificity of physical examination. Approximately $12 \%$ of amputees have DVT on routine ultrasound screening during admission to the acute rehabilitation unit [141]. In amputees receiving ACP, up to $26 \%$ develop symptomatic VTEs and in patients not receiving ACP, the rate can be as high as 50\% $[3,141,142]$. However, these studies are very small $(n=27$ and 8 patients, respectively) and thus may falsely elevate the incidence. DVTs can develop in both the residual and contralateral limb [141]. The presence of comorbidities, level of amputation, history of amputation, age, or race did not predict who would develop VTE [141].

However, these same authors note the patients that did develop VTE disease tend to have more proximal level of amputation, were older, had lower discharge Functional Independence Measure scores, and longer rehabilitation length of stays [141]. These authors also showed fewer instances of VTE disease in those that received prophylactic LDUFH versus no intervention [141]. Unexpected increases in swelling of the residual limb may suggest DVT [143]. Prophylaxis with LDUFH or MP should be considered in patients with immobility and risk factors. Years ago, if ACP was contraindicated, it was common to place the SCD on the sound limb (reduce venous stasis, enhance fibrinolytic activity) or even an upper extremity (enhance fibrinolytic activity only) to prevent thrombus formation [144]. It is accepted that SCDs will reduce venous stasis and help prevent a DVT in the lower extremities. However, the hypothesis of enhanced systemic fibrinolytic activity induced by the SCD as being protective against a thrombus formation is questioned. The systemic and local effects of compression activating fibrinolytic activity have not been demonstrated recently $[145,146]$. Therefore, effective and safe prophylaxis is provided only when the device is used in a manner that reduces lower extremity venous stasis. 


\section{Patients With Intracranial Injuries}

The next 3 major rehabilitation diagnoses discussed - stroke, traumatic brain injury, and neurosurgical patients—all share an increased risk of intracranial hemorrhage (ICH) relative to the other diagnoses discussed, but like other rehabilitation diagnoses, carry great risk for VTE. Furthermore, data are conflicting and limited for some scenarios. As such, decisions to use anticoagulation for VTE prophylaxis or treatment must be made with great care.

Stroke. The incidence of VTE in stroke patients varies widely, but the average is between $40 \%$ and $50 \%$ for DVTs and $10 \%$ for PEs [147]. VTE accounts for $1 \%$ to $2 \%$ of mortality of stroke patients in rehabilitation. DVTs most commonly develop 2 to 7 days after stroke but also occur thereafter. PEs are rare in the first week after stroke and peak during the second week [4]. In recent pooled stroke populations, DVT and PE rates were $5.1 \%$ and $0.74 \%$, respectively [148]. Fatal PEs occurred in 1\% to $13 \%$ of patients within the first 5 weeks of stroke onset $[148,149]$. Again, the clinical symptoms of DVT (pain, swelling, erythema) often may be absent in the stroke population. The risk of DVT is high in patients with the most severe neurological impairments, advanced age ( $>70$ years), lower limb plegia, obesity, previous history of VTE, and longer duration of hospital stay [150]. Surveillance should remain high in patients with additional risk factors for medical complications that include admission disability level, length of rehabilitation stay, low serum albumin level, prestroke disability, location of stroke in the anterior cerebral circulation region, and urinary incontinence $[4,151,152]$

In ischemic stroke patients, VTE prophylaxis may already be provided if patients are on warfarin; however, antiplatelet agents do not provide a VTE prophylaxis benefit $[153,154]$. In one study, concomitant use of aspirin with warfarin, targeted to an international normalized ratio (INR) of $\leq 2$ (mean 1.5) increased the 1-year risk of major hemorrhage from $0.7 \%$ to $1.7 \%$ [98]. In a separate cohort study, patients with ischemic stroke who are otherwise at a low risk for bleeding had no increased risk for bleeding with combined use of prophylactic heparin and antiplatelet agents [155]. A Cochrane systematic review of anticoagulants in patients with acute ischemic stroke found that VKA anticoagulation therapy resulted in $0.9 \%$ fewer recurrent ischemic strokes, $0.4 \%$ fewer symptomatic PEs, and $0.9 \%$ more symptomatic ICHs [156]. ICHs in ischemic stroke patients are often the result of hemorrhagic conversion, which is more common over the first 4 days and in larger strokes [157].

The incidence of VTE is greater in patients with hemorrhagic stroke than in patient with ischemic stroke $[148,158]$. This difference probably reflects an underuse of DVT prophylaxis in patients with hemorrhagic stroke because of concerns of hemorrhagic extension. This has led to SCDs being used in combination with an antiplatelet agent as the initial VTE prophylaxis with stroke patients. However, SCDs seem to provide only marginal benefit and compliance is not guaranteed [159]. LMWH has been found to be safe and effective for VTE prophylaxis in ischemic stroke patients and preferred over LDUFH (3 times a day dosing) and UFH because of its effectiveness and without a clear increase in ICH [160]. LMWH should be initiated between 24 and 48 hours after the event and even if there was administration of thrombolytic therapy $[98,161]$. Results with UFH have been less favorable because it is effective for DVT but not for PE $[154,160,162,163]$. The duration of VTE prophylaxis is poorly studied, but extended prophylaxis may be beneficial in patients with paresis [163]. It is suggested that patients that start LDUFH or LMWH within 48 hours of onset had a lower incidence in PE, without an increase of bleeding [164]. For patients with ICH, the initial use of SCDs is recommended. LDUFH or LMWH may be considered in patients with hemiplegia and may be initiated as soon as 48 to 72 hours after the onset of hemorrhage [164-166].

The cost effectiveness of performing ultrasound scans on all patients admitted to a stroke rehabilitation unit was calculated and not found to be cost effective, possibly secondary to the shorter expected life span in stroke patients relative to other rehabilitation diagnoses [167]. In treating VTEs, LMWH may be superior to VKAs for ease and safety [98].

Traumatic Brain Injury. Several authors have identified serious head injury to be an independent risk factor for DVT $[168,169]$. Different mechanisms have been proposed, to explain the increased risk of DVT formation among patients with traumatic brain injury (TBI), including immobilization, greater levels of circulating tissue factor, activation of the extrinsic pathway, vessel wall intimal damage leading to clot formation, and increased plasma levels of von Willebrand Factor [32,170-172],

In nontraumatic TBI patients, the bleeding risk with heparin prophylaxis was reported to be $<2 \%$ [90]. However, among TBI patients with LMWH, there have been reports of ICH of $3.2 \%$ and $9.1 \%$ in patients who required craniotomies when enoxaparin prophylaxis was initiated within 24 hours of the procedure [168]. As a result, there is fear of ICH with initiation of ACP in a timely fashion and so TBI patients often do not receive any ACP [170]. Some centers will use MP initially, but again, this should not be the primary prophylaxis. The latest guidelines on DVT prophylaxis in patients with TBI recommend the use of LMWH or LDUFH in combination with MP, especially when ACP is delayed initially $[32,92]$. Patients with long bone or pelvic fractures, previous DVT, obesity, other coagulopathies, or other identified elevated risk for DVT should be considered for more intensive anticoagulation with LMWH until fully mobilized $[169,173]$. The earliest proven safe time period for initiating ACP is a minimum of 36 hours after TBI $[32,166]$. In a prospective study of patients admitted to a level one trauma center with severe head injury, including subdural $\mathrm{ICH}$, the authors 
investigated the safety of LDUFH prophylaxis started before or after 72 hours of admission. Patients were cleared by neurosurgery before beginning LDUFH and were monitored hourly in the intensive care unit. Neither group had neurological deterioration nor increased hemorrhage on CT scans [174].

Because of the incidence of VTE and mortality involved in this population, the ability to detect VTE is of high priority. The reliability of signs, symptoms, and physical examination cannot be guaranteed. Use of the D-dimer as a screening tool has been evaluated in TBI patients who were being admitted to rehabilitation $[53,172,175,175]$. The interest was in a simple, cost-effective means to identify patients for VTE. In a prospective study from 2004, involving 360 TBI neurorehabilitation admissions, only the semiquantitative D-dimer and postinjury duration remained significant risk factors for proximal DVT in a multivariate analysis [176]. Patients with the greatest titers of the semiquantitative latex agglutination assay were reliably correlated with a DVT. The science of D-dimer has continued to evolve, and the modified ELISA method has been shown to be superior to those of other D-dimer methods in its negative predictive value [177].

The incidence of DVT in the acute rehabilitation setting after TBI varies widely according to observational studies [172]. Those study authors that use DUS admission screening report greater DVT incidences than those who rely upon symptoms for detection. The incidence ranges from $8.5 \%$ to $18 \%$ when asymptomatic DUS screening is used $[176,178,179]$. Because of the incidence of VTE and mortality involved in this population, the ability to detect VTE is of high priority. The reliability of signs, symptoms, and physical examination cannot be guaranteed. A survey of the Traumatic Brain Injury Model System revealed no consensus regarding the optimal methods for screening, prevention, or treatment of VTE in TBI patients in the acute rehabilitation setting. Of the centers that responded to the survey, approximately one-half routinely screen to detect subclinical DVTs (56\% use DUS, 13\% use DUS and D-dimer together, and 31\% use leg circumference measurements) on admission to inpatient acute rehabilitation. In addition, the rehabilitation units reported greater use of ACP than trauma. Overall, MP was the most common method of DVT prophylaxis than ACP in the TBI in trauma and rehabilitation populations [172]. DUS on admission to acute rehabilitation is cost effective and recommended because of lives saved $[178,179]$. Fortunately, the incidence of symptomatic PE remains low and is reported at 0.38\% [180]. Factors that increased the risk of PE in head trauma patients were age older than 45 years, male gender, injury severity scale score greater than 15 , and concomitant SCI, pelvic fracture, or femur fracture [180].

Craniotomies. In neurosurgical patients, the risk of VTE and hemorrhage varies among patient groups. Neurosurgery patients often have multiple risk factors for the development of DVTs and also bear the risk of catastrophic PE. In several randomized controlled trials of general neurosurgery patients, the rate of symptomatic DVT was 22\%, of which $5 \%$ were proximal. Neurosurgical patients with incision of the meninges have a 2- to 3-fold greater rate of VTE than mixed surgical patient populations. Intracranial (versus spinal) surgery, malignancy, prolonged procedures, leg weakness, and advanced age have all been shown to increase the rate of VTE in these patients [32]. Patients with malignant brain tumors are at particularly high risk for VTE, both perioperatively and during subsequent follow-up [181-183]. It has been reported that $50 \%$ to $66 \%$ of VTEs in neurosurgery patients occur after discharge from the hospital $[13,183]$.

SCDs typically are used for neurosurgery patients because of concern for ICH. In one retrospective study of pooled neurosurgery patients with SCDs, the risk was lowered from $22 \%$ to $7 \%$ [81]. Another study showed symptomatic DVTs occur in $10 \%$ to $31 \%$ of patients receiving VTE prophylaxis solely with SCDs [184]. Given the rate of VTE, chemical prophylaxis is needed, and the risk/benefit ratio must be weighed. In some centers, mechanical thromboprophylaxis is started at the time of surgery; then, if a CT scan obtained the following day does not show bleeding, anticoagulant thromboprophylaxis is either added or substituted. The authors of prospective studies have not demonstrated the risk of intracranial bleeding to be increased in neurosurgical patients who received perioperative LDUFH thromboprophylaxis [185-187]. However, caution should be exercised when considering the use of preoperative or early postoperative LMWH in craniotomy patients $[185,186,188,189]$. Most bleeds occur within 2 days after surgery. When LMWH is started after 48 hours after surgery, the results are favorable for VTE protection without increased incidence of hemorrhage $[165,190]$. The use of enoxaparin at $20 \mathrm{mg}$ once daily (reduced dose) has shown promising results in a small study [191]. Starting ACP preoperatively appears to have a significantly greater risk $(6.1 \%$ versus $3 \%)$ of $\mathrm{ICH}$ relative to postoperative initiation $[166,189,192]$.

Recommended VTE prophylaxis for high-risk patients undergoing intracranial surgery is a multimodal approach with SCDs, with or without GCS, with initiation of ACP when appropriate [32,193]. For normal-risk patients undergoing elective neurosurgery, prophylaxis is with SCDs, as well as, early and frequent ambulation [165].

\section{MECHANICAL PROPHYLAXIS, AMBULATION, ORTHOSES, AND RETURN TO THERAPY}

The risk of embolization of DVT is thought to be greatest soon after its formation when it is loosely attached to the blood vessel wall [32]. In an effort to prevent embolization of a newly identified DVT, an interval of bed rest is often prescribed [194]. During this period, anticoagulation treatment is used to prevent clot propagation and to allow orga- 
nization of the clot. Subsequent adherence of the clot to the endothelial lining of the blood vessel is thought to render it less likely to result in PE once the patient becomes mobile.

The optimum interval of bed rest has not been identified in the literature. In patients diagnosed with VTE, prolonged bed rest is not indicated, and ambulation is safe and should be encouraged. Although a retrospective study previously reported that rehabilitation patients with DVT who subsequently developed PE had returned to active physiotherapy earlier (average 48 hours) than those who did not develop PE (average 123 hours), this study had a number of limitations, including that only 6 patients with PE were studied and there was no screening for asymptomatic PE at the time of study entry $[195,196]$.

The authors of a systematic review found no supporting data to halt physical therapy for 24 to 48 hours to prevent clot propagation after initiation of LMWH treatment for VTE [42]. Studies in which the investigators compare early ambulation and bed rest have found no statistically significant difference in the progression rate of PE [197-201]. GCS can be continued after diagnosis of acute DVT because there is a minimal risk of propagation from their use. Ambulation should be encouraged and bed rest discouraged because ambulation may promote thrombus resolution and decreases the risk of PTS $[42,196]$. Although ambulation reduces VTE risk, no specific distance has been validated as sufficient to discontinue prophylaxis. In patients in whom ACP is contraindicated, SCDs can be used after diagnosis of an acute DVT and insertion of IVCF should be evaluated [144]. There have been case reports of DVT development in patients with AFO use $[202,203]$. Although not common, physiatrists should be aware of this association.

\section{TREATMENT DURATION}

The optimal duration of treatment for VTE is not well defined, but currently, a 3- to 6-month course of anticoagulation therapy is common and has been shown to decrease VTE recurrence or progression [36]. Because the first 3 months are the greatest risk of recurrent VTE and bleeding, the value of treatment beyond the 3-month time period is less certain, and the risk of recurrence versus the bleeding risk need to be balanced [204]. The annual incidence of bleeding in pooled patients being treated for VTE with warfarin is $2 \%$, and fatal bleeding risk is $0.3 \%$ [205]. The challenge in drawing a conclusion on the best practice relates to the fact that $80 \%$ to $90 \%$ of recurrent VTE occurs after discontinuation of therapy. For patients without ongoing risk factors and high bleeding risk, treatment beyond 3 months may have an increased risk/benefit ratio with limited benefit [206]. However, consideration should be given to indefinite anticoagulation in patients with additional risk factors, especially those with PE, because the risk for fatal recurrence is 4 times greater in these patients [207]. One approach is to measure the D-dimer value 1 month after stopping oral anticoagulation. If it is abnormal, one should consider restarting anticoagulation to decrease recurrent thromboembolism [208, 209].

To avoid the risk for bleeding complications and the inconvenience for patients of being on extended or indefinite warfarin treatment, the authors of a number of studies are currently evaluating different management strategies for secondary prevention of recurrent VTE after a conventional 3- to 6-month oral anticoagulant treatment. Two recent trials evaluated the opportunity to extend oral anticoagulation with low-intensity warfarin (INR 1.5-2.0) after an initial treatment of 3 to 6 months of conventional-intensity anticoagulation (INR 2.0-3.0) [210,211]. The first of these studies showed superior efficacy of low-intensity anticoagulant regimen compared with placebo in the prevention of recurrent VTE [211]. However, in a subsequent study, the low-intensity regimen was in place from initial treatment and extended beyond 3 months. This protocol has been shown to be less effective than the conventional intensity regimen for the prevention of recurrent VTE without providing any advantage in terms of reduction of bleeding complications [210]. General guidelines are outlined in Table 6 .

\section{CONCLUSIONS}

The current literature does not provide rigid clinical pathways regarding the prophylaxis and treatment of VTEs in rehabilitation patients. Given the heterogeneity of rehabilitation patients and the often dramatically elevated VTE and bleeding risks, such literature

Table 6. VTE treatment guidelines

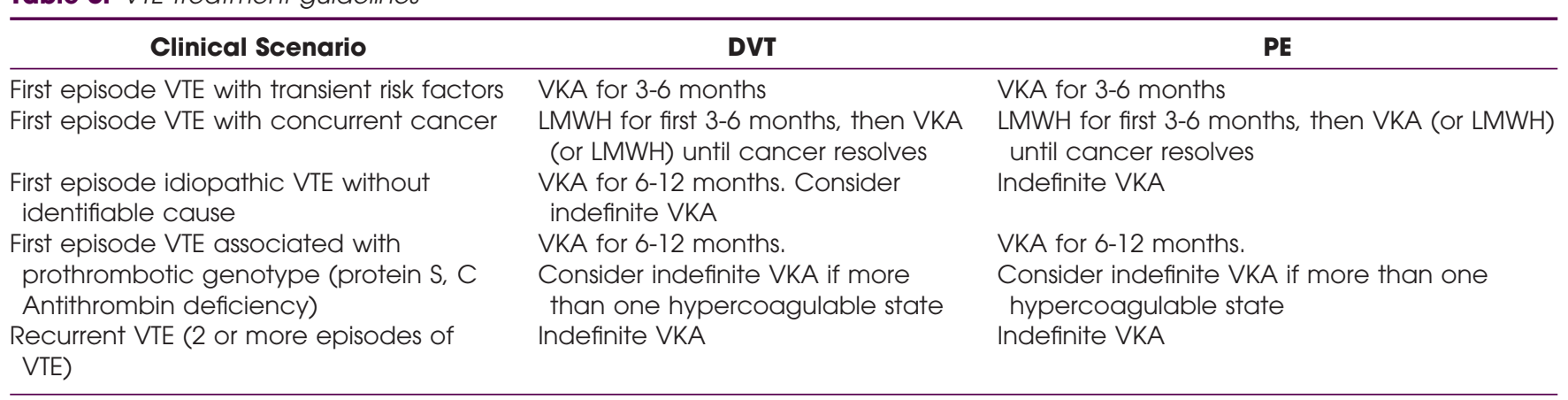

$\mathrm{DVT}=$ deep vein thrombosis; LMWH = low-molecular-weight heparin; PE = pulmonary embolism; VKA = vitamin $\mathrm{K}$ agonist; VTE = venous thromboembolism. 
is unlikely to be available in the near future. Fortunately, there is ample data which can improve the clinical management of VTEs in rehabilitation patients

In reviewing VTE risk factors, it is apparent that most rehabilitation patients typically fall into several major categories for the development of VTE events and carry several risk factors that increase the likelihood of such events. Consequently, the rehabilitation team must always be vigilant for the development of VTEs, when doing consults, during acute rehabilitation, and for several months after discharge. This vigilance should include inquiring about VTEs in the medical histories with every physical, and looking for VTEs during postdischarge follow-up appointments. Patients should use compression stockings for at least 2 years after development of DVT to reduce the risk of PTS.

VTE prophylaxis for rehabilitation patients is often limited to MP because of a risk of bleeding. However, patient compliance with SCD is often very low for many reasons. As such, efforts should be made to maximize compliance, both before and during rehabilitation. In general, MP is less efficacious than ACP. Some patients with a high risk of bleeding can still receive ACP. For patients receiving ACP, LMWH is preferred over UFH for cancer, SCI, trauma, and orthopedic surgery.

The duration of prophylaxis for most patients is determined on the basis of the clinical situation and not well defined; however, prophylaxis should be proportionally longer for patients with residual risk factors. Although ambulation reduces VTE risk, no specific distance has been validated as sufficient to discontinue prophylaxis.

The number of fatal pulmonary emboli reported by survey respondents has highlighted the importance of developing evidence-based guidelines for prevention and treatment of DVT and PE in our patient population. Moreover, the substantial variability in practice patterns across other rehabilitation units suggests that prospective observational study will yield further insight into DVT prevention and management methods during acute inpatient rehabilitation.

\section{ACKNOWLEDGMENTS}

In memory of Brian M. Yoder, MD (1968-2009). Dr. Yoder graduated from Northland High School in 1986. He completed his undergraduate degree in Industrial and Systems Engineering at Ohio University in 1990 and went to work at EDS, General Motors in Detroit. Brian graduated from the University of Michigan Medical School in 2000 and was employed by the Wayne State Physician Group.

Dr. Yoder is survived by his wife, Theresa and his sons, Alex and Will. Dr. Yoder strived to make people laugh and engage in life. He was dedicated to bringing warmth and joy to others and was often the subject of his own practical pranks to spark laughter in others. He will be remembered for his signature bow tie, positive outlook, and enjoyment of outdoor adventures. Dr. Yoder was an excellent physician, teacher, husband, father, and good friend. He will be missed by all those who loved and respected him.

\section{REFERENCES}

1. Siegler EL, Stineman MG, Maislin G. Development of complications during rehabilitation. Arch Intern Med 1994;154:2185-2190.

2. Chen D, Apple DF Jr, Hudson LM, Bode R. Medical complications during acute rehabilitation following spinal cord injury-current experience of the Model Systems. Arch Phys Med Rehabil 1999;80: 1397-1401.

3. Burke B, Kumar R, Vickers V, Grant E, Scremin E. Deep vein thrombosis after lower limb amputation. Am J Phys Med Rehabil 2000;79: 145-149.

4. Roth EJ, Lovell L, Harvey RL, Heinemann AW, Semik P, Diaz S Incidence of and risk factors for medical complications during stroke rehabilitation. Stroke 2001;32:523-529.

5. Carney ML, Ullrich P, Esselman P. Early unplanned transfers from inpatient rehabilitation. Am J Phys Med Rehabil 2006;85:453-460; quiz 461-453.

6. Shorr AF. The pharmacoeconomics of deep vein thrombosis treatment. Am J Med 2007;120(10 Suppl 2):S35-S41.

7. de Lissovoy G. Economic issues in the treatment and prevention of deep vein thrombosis from a managed care perspective. Am J Manage Care 2001;7(17 Suppl):S535-538; discussion S538-544.

8. Merkel A. Origin and natural history of deep vein thrombosis of the legs. Sem Vasc Med 2005;5:10

9. Heit JA, Silverstein MD, Mohr DN, Petterson TM, O'Fallon WM Melton LJ 3rd. Risk factors for deep vein thrombosis and pulmonary embolism: A population-based case-control study. Arch Intern Med 2000;160:809-815

10. Blom JW, Doggen CJ, Osanto S, Rosendaal FR. Malignancies, prothrombotic mutations, and the risk of venous thrombosis. JAMA 2005;293:715-722

11. Anderson FA Jr, Wheeler HB, Goldberg RJ, et al. A population-based perspective of the hospital incidence and case-fatality rates of deep vein thrombosis and pulmonary embolism. The Worcester DVT Study. Arch Intern Med 1991;151:933-938

12. Motykie GD, Zebala LP, Caprini JA, et al. A guide to venous thromboembolism risk factor assessment. J Thromb Thrombolysis 2000;9: 253-262.

13. White RH, Zhou H, Romano PS. Incidence of symptomatic venous thromboembolism after different elective or urgent surgical procedures. Thromb Haemost 2003;90:446-455.

14. Ageno W, Squizzato $A$, Garcia $D$, Imberti D. Epidemiology and risk factors of venous thromboembolism. Semin Thromb Hemost 2006; 32:651-658.

15. Agnelli G, Becattini C. Treatment of DVT: How long is enough and how do you predict recurrence. J Thromb Thrombolysis 2008;25:37-44.

16. Hull RD, Hirsh J, Carter CJ, et al. Pulmonary angiography, ventilation lung scanning, and venography for clinically suspected pulmonary embolism with abnormal perfusion lung scan. Ann Intern Med 1983; 98:891-899.

17. Rollins DL, Semrow CM, Friedell ML, Lloyd WE, Buchbinder D. Origin of deep vein thrombi in an ambulatory population. Am J Surg 1988; 156:122-125

18. Meignan $M$, Rosso J, Gauthier $H$, et al. Systematic lung scans reveal a high frequency of silent pulmonary embolism in patients with proximal deep venous thrombosis. Arch Intern Med 2000;160:159-164.

19. Kearon C. Natural history of venous thromboembolism. Circulation 2003;107(23 Suppl 1):122-130.

20. Markel A. Origin and natural history of deep vein thrombosis of the legs. Semin Vasc Med 2005;5:65-74 
21. Lagerstedt CI, Olsson CG, Fagher BO, Oqvist BW, Albrechtsson U. Need for long-term anticoagulant treatment in symptomatic calf-vein thrombosis. Lancet 1985;2:515-518.

22. Schulman $S$, Rhedin AS, Lindmarker $P$, et al. A comparison of six weeks with six months of oral anticoagulant therapy after a first episode of venous thromboembolism. Duration of Anticoagulation Trial Study Group. N Engl J Med 1995;332:1661-1665.

23. Prandoni $\mathrm{P}$, Lensing AW, Cogo A, et al. The long-term clinical course of acute deep venous thrombosis. Ann Intern Med 1996;125:1-7.

24. Decousus $H$, Leizorovicz A, Parent $F$, et al. A clinical trial of vena caval filters in the prevention of pulmonary embolism in patients with proximal deep-vein thrombosis. Prevention du Risque d'Embolie Pulmonaire par Interruption Cave Study Group. N Engl J Med 1998; 338:409-415.

25. Hansson PO, Sorbo J, Eriksson $H$. Recurrent venous thromboembolism after deep vein thrombosis: Incidence and risk factors. Arch Intern Med 27 2000;160:769-774.

26. Cushman M, Glynn RJ, Goldhaber SZ, et al. Hormonal factors and risk of recurrent venous thrombosis: The prevention of recurrent venous thromboembolism trial. J Thromb Haemost 2006;4:2199-2203.

27. Heit JA, Silverstein MD, Mohr DN, Petterson TM, O'Fallon WM, Melton LJ 3rd. Predictors of survival after deep vein thrombosis and pulmonary embolism: A population-based, cohort study. Arch Intern Med 1999; 159:445-453

28. Heit JA, Mohr DN, Silverstein MD, Petterson TM, O'Fallon WM, Melton LJ 3rd. Predictors of recurrence after deep vein thrombosis and pulmonary embolism: A population-based cohort study. Arch Intern Med 2000;160:761-768.

29. Kommareddy A, Zaroukian MH, Hassouna HI. Upper extremity deep venous thrombosis. Semin Thromb Hemost 2002;28:89-99.

30. Arnhjort T, Persson LM, Rosfors S, Ludwigs U, Larfars G. Primary deep vein thrombosis in the upper limb: A retrospective study with emphasis on pathogenesis and late sequelae. Eur J Intern Med 2007; 18:304-308.

31. Mason RJ, Murray JF, Broaddus BC, et al eds. Murray \& Nadel's Textbook of Respiratory Medicine. 4th ed. Philadelphia: Saunders; 2005.

32. Geerts WH, Bergqvist D, Pineo GF, et al. Prevention of venous thromboembolism: American College of Chest Physicians EvidenceBased Clinical Practice Guidelines (8th edition). Chest 2008;133(6 Suppl):381S-453S

33. Prandoni $\mathrm{P}$, Bernardi $\mathrm{E}$, Marchiori $\mathrm{A}$, et al. The long term clinical course of acute deep vein thrombosis of the arm: prospective cohort study. BMJ 2004;329:484-485

34. Brandjes DP, Buller HR, Heijboer $\mathrm{H}$, et al. Randomised trial of effect of compression stockings in patients with symptomatic proximal-vein thrombosis. Lancet 1997;349:759-762.

35. Mohr DN, Silverstein MD, Heit JA, Petterson TM, O'Fallon WM, Melton LJ. The venous stasis syndrome after deep venous thrombosis or pulmonary embolism: A population-based study. Mayo Clin Proc 2000;75:1249-1256.

36. Kearon C, Kahn SR, Agnelli G, Goldhaber S, Raskob GE, Comerota AJ. Antithrombotic therapy for venous thromboembolic disease: American College of Chest Physicians Evidence-Based Clinical Practice Guidelines. 8th ed. Chest 2008;133(6 Suppl):454S-545S.

37. Kahn SR, Elman EA, Bornais C, Blostein M, Wells PS. Post-thrombotic syndrome, functional disability and quality of life after upper extremity deep venous thrombosis in adults. Thromb Haemost 2005;93: 499-502.

38. Kahn SR, Ginsberg JS. Relationship between deep venous thrombosis and the postthrombotic syndrome. Arch Intern Med 2004;164:17-26.

39. Ashrani AA, Heit JA. Incidence and cost burden of post-thrombotic syndrome. J Thromb Thrombolysis 2009;28:465-476.
40. Kolbach DN, Sandbrink MW, Hamulyak K, Neumann HA, Prins MH Non-pharmaceutical measures for prevention of post-thrombotic syndrome. Cochrane Database Syst Rev 2004;(1):CD004174.

41. Ginsberg JS, Magier D, Mackinnon B, Gent M, Hirsh J. Intermittent compression units for severe post-phlebitic syndrome: A randomized crossover study. CMAJ 1999;160:1303-1306.

42. Trujillo-Santos J, Perea-Milla E, Jimenez-Puente A, et al. Bed rest or ambulation in the initial treatment of patients with acute deep vein thrombosis or pulmonary embolism: Findings from the RIETE registry. Chest 2005; 127:1631-1636.

43. Wells PS, Owen C, Doucette S, Fergusson D, Tran H. Does this patient have deep vein thrombosis? JAMA 2006;295:199-207.

44. Anand SS, Wells PS, Hunt D, Brill-Edwards P, Cook D, Ginsberg JS. Does this patient have deep vein thrombosis? JAMA 1998;279:10941099.

45. Righini $M$, Goehring $C$, Bounameaux $H$, Perrier A. Effects of age on the performance of common diagnostic tests for pulmonary embolism. Am J Med 2000;109:357-361.

46. Bosson JL, Barro C, Satger B, Carpentier PH, Polack B, Pernod G. Quantitative high D-dimer value is predictive of pulmonary embolism occurrence independently of clinical score in a well-defined low risk factor population. J Thromb Haemost 2005;3:93-99.

47. Bosson JL, Labarere J, Sevestre MA, et al. Deep vein thrombosis in elderly patients hospitalized in subacute care facilities: A multicenter cross-sectional study of risk factors, prophylaxis, and prevalence. Arch Intern Med 2003;163:2613-2618.

48. Imberti D. D-dimer testing: Advantages and limitations in emergency medicine for managing acute venous thromboembolism. Intern Emerg Med 2007;2:70-71.

49. Heim SW, Schectman JM, Siadaty MS, Philbrick JT. D-dimer testing for deep venous thrombosis: A metaanalysis. Clin Chem 2004;50: $1136-1147$

50. Janssen MC, Wollersheim H, Verbruggen B, Novakova IR. Rapid D-dimer assays to exclude deep venous thrombosis and pulmonary embolism: Current status and new developments. Semin Thromb Hemost 1998;24:393-400.

51. Janssen MC, Heebels AE, de Metz M, et al. Reliability of five rapid D-dimer assays compared to ELISA in the exclusion of deep venous thrombosis. Thromb Haemost 1997;77:262-266.

52. Wells $P S$, Anderson DR, Rodger $M$, et al. Evaluation of $D$-dimer in the diagnosis of suspected deep-vein thrombosis. N Engl J Med 2003;349: 1227-1235.

53. Akman $M N$, Cetin $N$, Bayramoglu $M$, Isiklar I, Kilinc S. Value of the D-dimer test in diagnosing deep vein thrombosis in rehabilitation inpatients. Arch Phys Med Rehabil 2004;85:1091-1094.

54. Birdwell B. Recent clinical trials in the diagnosis of deep-vein thrombosis. Curr Opin Hematol 1999;6:275-279.

55. Tan M, van Rooden CJ, Westerbeek RE, Huisman MV. Diagnostic management of clinically suspected acute deep vein thrombosis. Br J Haematol 2009;146:347-360.

56. Streiff MB. Diagnosis and initial treatment of venous thromboembolism in patients with cancer. J Clin Oncol 2009;27:4889-4894.

57. Goodacre S, Sampson F, Stevenson M, et al. Measurement of the clinical and cost-effectiveness of non-invasive diagnostic testing strategies for deep vein thrombosis. Health Technol Assess 2006;10:1168, iii-iv.

58. Michiels JJ, Gadisseur A, Van Der Planken M, et al. A critical appraisal of non-invasive diagnosis and exclusion of deep vein thrombosis and pulmonary embolism in outpatients with suspected deep vein thrombosis or pulmonary embolism: How many tests do we need? Int Angiol 2005;24:27-39.

59. Wells PS, Anderson DR. Modern approach to diagnosis in patients with suspected deep vein thrombosis. Haemostasis 1999;29(Suppl S1): $10-20$. 
60. Wells PS, Anderson DR, Ginsberg J. Assessment of deep vein thrombosis or pulmonary embolism by the combined use of clinical model and noninvasive diagnostic tests. Semin Thromb Hemost 2000;26: 643-656.

61. Wells PS. Advances in the diagnosis of venous thromboembolism. J Thromb Thrombolysis. 2006;21:31-40.

62. Wells PS, Ginsberg JS, Anderson DR, et al. Use of a clinical model for safe management of patients with suspected pulmonary embolism. Ann Intern Med 1998;129:997-1005

63. Wells PS, Anderson DR, Rodger M, et al. Derivation of a simple clinical model to categorize patients probability of pulmonary embolism: Increasing the models utility with the SimpliRED D-dimer. Thromb Haemost 2000;83:416-420.

64. Mayo JR, Remy-Jardin M, Muller NL, et al. Pulmonary embolism: Prospective comparison of spiral CT with ventilation-perfusion scintigraphy. Radiology 1997;205:447-452

65. Stein PD, Fowler SE, Goodman LR, et al. Multidetector computed tomography for acute pulmonary embolism. N Engl J Med. Jun 1 2006;354(22):2317-2327.

66. Rodger MA, Carrier M, Jones GN, et al. Diagnostic value of arterial blood gas measurement in suspected pulmonary embolism. Am J Respir Crit Care Med 2000;162:2105-2108.

67. Stein PD, Woodard PK, Weg JG, et al. Diagnostic pathways in acute pulmonary embolism: Recommendations of the PIOPED II Investigators. Radiology 2007;242:15-21.

68. Kadyan V, Clinchot DM, Colachis SC. Cost-effectiveness of duplex ultrasound surveillance in spinal cord injury. Am J Phys Med Rehabil 2004:83:191-197.

69. Merli GJ, Herbison GJ, Ditunno JF, et al. Deep vein thrombosis: Prophylaxis in acute spinal cord injured patients. Arch Phys Med Rehabil 1988;69:661-664

70. Myllynen $P$, Kammonen M, Rokkanen $P$, Bostman $O$, Lalla M, Laasonen E. Deep venous thrombosis and pulmonary embolism in patients with acute spinal cord injury: A comparison with nonparalyzed patients immobilized due to spinal fractures. J Trauma 1985; 25:541-543

71. Seifert J, Lob G, Stoephasius E, Probst J, Brendel W. Blood flow in muscles of paraplegic patients under various conditions measured by a double isotope technique. Paraplegia 1972;10:185-191.

72. Rossi EC, Green D, Rosen JS, Spies SM, Jao JS. Sequential changes in factor VIII and platelets preceding deep vein thrombosis in patients with spinal cord injury. Br J Haematol 1980;45:143-151.

73. Winther K, Gleerup G, Snorrason K, Biering-Sorensen F. Platelet function and fibrinolytic activity in cervical spinal cord injured patients. Thromb Res 1992;65:469-474

74. Ersoz G, Ficicilar H, Pasin M, Yorgancioglu R, Yavuzer S. Platelet aggregation in traumatic spinal cord injury. Spinal Cord 1999;37: 644-647.

75. Sipski ML, Richards JS. Spinal cord injury rehabilitation: State of the science. Am J Phys Med Rehabil 2006;85:310-342

76. Jones T, Ugalde V, Franks P, Zhou H, White RH. Venous thromboembolism after spinal cord injury: Incidence, time course, and associated risk factors in 16,240 adults and children. Arch Phys Med Rehabil 2005:86:2240-2247.

77. Geerts WH, Jay RM, Code KI, et al. A comparison of low-dose heparin with low-molecular-weight heparin as prophylaxis against venous thromboembolism after major trauma. N Engl J Med 1996;335:701707.

78. Prevention of venous thromboembolism in the rehabilitation phase after spinal cord injury: Prophylaxis with low-dose heparin or enoxaparin. J Trauma 2003;54:1111-1115.

79. Prevention of thromboembolism in spinal cord injury. Consortium for Spinal Cord Medicine. J Spinal Cord Med 1997;20:259-283

80. Prevention of venous thromboembolism in the acute treatment phase after spinal cord injury: A randomized, multicenter trial comparing low-dose heparin plus intermittent pneumatic compression with enoxaparin. J Trauma 2003;54:1116-1124; discussion 1125-1116.

81. Geerts WH, Bergqvist D, Pineo GF, et al. Prevention of venous thromboembolism: American College of Chest Physicians EvidenceBased Clinical Practice Guidelines (8th Edition). Chest 2008;133 381S-453S

82. Aito S, Pieri A, D'Andrea M, Marcelli F, Cominelli E. Primary prevention of deep venous thrombosis and pulmonary embolism in acute spinal cord injured patients. Spinal Cord 2002;40:300-303.

83. Furlan JC, Fehlings MG. Role of screening tests for deep venous thrombosis in asymptomatic adults with acute spinal cord injury: An evidence-based analysis. Spine (Phila Pa 1976) 2007;32:1908-1916.

84. Powell M, Kirshblum $S$, O'Connor KC. Duplex ultrasound screening for deep vein thrombosis in spinal cord injured patients at rehabilitation admission. Arch Phys Med Rehabil 1999;80:1044-1046.

85. Gorman PH, Qadri SF, Rao-Patel A. Prophylactic inferior vena cava (IVC) filter placement may increase the relative risk of deep venous thrombosis after acute spinal cord injury. J Trauma 2009;66:707-712.

86. Becker DM, Philbrick JT, Selby JB. Inferior vena cava filters. Indications, safety, effectiveness. Arch Intern Med 1992;152:1985-1994

87. Sing RF, Camp SM, Heniford BT, et al. Timing of pulmonary emboli after trauma: Implications for retrievable vena cava filters. J Trauma 2006; 60:732-734; discussion 734-735

88. Rogers FB. Venous thromboembolism in trauma patients: A review Surgery 2001;130:1-12.

89. Shackford SR, Mackersie RC, Holbrook TL, et al. The epidemiology of traumatic death. A population-based analysis. Arch Surg 1993;128 571-575.

90. Knudson MM, Ikossi DG. Venous thromboembolism after trauma Curr Opin Crit Care 2004;10:539-548.

91. Ginzburg E, Cohn SM, Lopez J, Jackowski J, Brown M, Hameed SM. Randomized clinical trial of intermittent pneumatic compression and low molecular weight heparin in trauma. Br J Surg 2003;90:13381344 .

92. Stannard JP, Lopez-Ben RR, Volgas DA, et al. Prophylaxis against deep-vein thrombosis following trauma: A prospective, randomized comparison of mechanical and pharmacologic prophylaxis. J Bone Joint Surg Am 2006;88:261-266

93. Fuchs S, Heyse T, Rudofsky G, Gosheger G, Chylarecki C. Continuous passive motion in the prevention of deep-vein thrombosis: A randomised comparison in trauma patients. J Bone Joint Surg Br 2005;87:1117-1122

94. Meissner MH, Chandler WL, Elliott JS. Venous thromboembolism in trauma: A local manifestation of systemic hypercoagulability? J Trauma 2003;54:224-231.

95. Rogers FB, Cipolle MD, Velmahos G, Rozycki G, Luchette FA. Practice management guidelines for the prevention of venous thromboembolism in trauma patients: The EAST practice management guidelines work group. J Trauma 2002;53:142-164

96. Borer DS, Starr AJ, Reinert CM, et al. The effect of screening for deep vein thrombosis on the prevalence of pulmonary embolism in patients with fractures of the pelvis or acetabulum: A review of 973 patients. J Orthop Trauma 2005; 19:92-95.

97. Cipolle MD, Wojcik R, Seislove E, Wasser TE, Pasquale MD. The role of surveillance duplex scanning in preventing venous thromboembolism in trauma patients. J Trauma 2002;52:453-462.

98. Levine MN, Raskob G, Beyth RJ, Kearon C, Schulman S. Hemorrhagic complications of anticoagulant treatment: The Seventh ACCP Conference on Antithrombotic and Thrombolytic Therapy. Chest 2004 126(3 Suppl):287S-310S.

99. Young T, Aukes J, Hughes R, Tang H. Vena caval filters for the prevention of pulmonary embolism. Cochrane Database Syst Rev 2007(3):CD006212. 
100. Girard TD, Philbrick JT, Fritz Angle J, Becker DM. Prophylactic vena cava filters for trauma patients: A systematic review of the literature. Thromb Res 2003;112:261-267.

101. Spain DA, Richardson JD, Polk HC Jr., Bergamini TM, Wilson MA, Miller FB. Venous thromboembolism in the high-risk trauma patient: Do risks justify aggressive screening and prophylaxis? J Trauma 1997;42:463-467; discussion 467-469.

102. Joels CS, Sing RF, Heniford BT. Complications of inferior vena cava filters. Am Surg 2003;69:654-659.

103. Antevil JL, Sise MJ, Sack DI, et al. Retrievable vena cava filters for preventing pulmonary embolism in trauma patients: A cautionary tale. J Trauma 2006;60:35-40.

104. Cothren CC, Smith WR, Moore EE, Morgan SJ. Utility of once-daily dose of low-molecular-weight heparin to prevent venous thromboembolism in multisystem trauma patients. World J Surg 2007;31:98104.

105. Given MF, McDonald BC, Brookfield $P$, et al. Retrievable Gunther Tulip inferior vena cava filter: Experience in 317 patients. J Med Imaging Radiat Oncol 2008;52:452-457.

106. Faucher LD, Conlon KM. Practice guidelines for deep venous thrombosis prophylaxis in burns. J Burn Care Res 2007;28:661-663.

107. Buller HR, Agnelli G, Hull RD, Hyers TM, Prins MH, Raskob GE. Antithrombotic therapy for venous thromboembolic disease: The Seventh ACCP Conference on Antithrombotic and Thrombolytic Therapy. Chest 2004;126(3 Suppl):401S-428S.

108. Barret JP, Dziewulski PG. Complications of the hypercoagulable status in burn injury. Burns 2006;32:1005-1008.

109. Douketis JD, Gu C, Piccioli A, Ghirarduzzi A, Pengo V, Prandoni P. The long-term risk of cancer in patients with a first episode of venous thromboembolism. J Thromb Haemost 2009;7:546-551

110. Arkel YS. Thrombosis and cancer. Semin Oncol 2000;27:362-374.

111. Descourt R, Le Gal G, Couturaud F, et al. Recurrent venous thromboembolism under anticoagulant therapy: A high risk in adenocarcinoma? Thromb Haemost 2006;95:912-913.

112. Sorensen HT, Mellemkjaer L, Olsen JH, Baron JA. Prognosis of cancers associated with venous thromboembolism. N Engl J Med 2000;343:1846-1850

113. Chew HK, Wun $T$, Harvey $D$, Zhou $H$, White RH. Incidence of venous thromboembolism and its effect on survival among patients with common cancers. Arch Intern Med 2006;166:458-464.

114. Alcalay A, Wun $T$, Khatri $V$, et al. Venous thromboembolism in patients with colorectal cancer: Incidence and effect on survival. J Clin Oncol 2006;24:1112-1118

115. Heit JA. Venous thromboembolism epidemiology: Implications for prevention and management. Semin Thromb Hemost 2002;28(Suppl 2):3-13.

116. Heit JA. Cancer and venous thromboembolism: Scope of the problem. Cancer Control 2005;12(Suppl 1):5-10.

117. Bergqvist D, Caprini JA, Dotsenko O, Kakkar AK, Mishra RG, Wakefield TW. Venous thromboembolism and cancer. Curr Probl Surg 2007:44:157-216.

118. Agnelli G, Bolis G, Capussotti L, et al. A clinical outcome-based prospective study on venous thromboembolism after cancer surgery: The @RISTOS project. Ann Surg 2006;243:89-95.

119. Bergqvist D, Agnelli G, Cohen AT, et al. Duration of prophylaxis against venous thromboembolism with enoxaparin after surgery for cancer. N Engl J Med 2002;346:975-980.

120. Rasmussen MS. Preventing thromboembolic complications in cancer patients after surgery: A role for prolonged thromboprophylaxis. Cancer Treat Rev 2002;28:141-144.

121. Gathof BS, Picker SM, Rojo J. Epidemiology, etiology and diagnosis of venous thrombosis. Eur J Med Res 2004;9:95-103

122. Noble SI, Nelson A, Turner C, Finlay IG. Acceptability of low molecular weight heparin thromboprophylaxis for inpatients receiving palliative care: Qualitative study. BMJ 2006;332:577-580.
123. Wagman LD, Baird MF, Bennett CL, et al. Venous thromboembolic disease. Clinical practice guidelines in oncology. J Natl Compr Canc Netw 2006;4:838-869

124. Lee AY, Levine MN, Baker RI, et al. Low-molecular-weight heparin versus a coumarin for the prevention of recurrent venous thromboembolism in patients with cancer. N Engl J Med 2003;349:146-153.

125. Martel N, Lee J, Wells PS. Risk for heparin-induced thrombocytopenia with unfractionated and low-molecular-weight heparin thromboprophylaxis: A meta-analysis. Blood 2005;106:2710-2715.

126. Linenberger ML. Catheter-related thrombosis: Risks, diagnosis, and management. J Natl Compr Canc Netw 2006;4:889-901

127. Kovacs MJ, Kahn SR, Rodger M, et al. A pilot study of central venous catheter survival in cancer patients using low-molecular-weight heparin (dalteparin) and warfarin without catheter removal for the treatment of upper extremity deep vein thrombosis (The Catheter Study). J Thromb Haemost 2007; 5:1650-1653.

128. Nguyen NP, Borok TL, Welsh J, Vinh-Hung V. Safety and effectiveness of vascular endoprosthesis for malignant superior vena cava syndrome. Thorax 2009;64:174-178.

129. Prandoni $P$, Lensing AW, Piccioli $A$, et al. Recurrent venous thromboembolism and bleeding complications during anticoagulant treatment in patients with cancer and venous thrombosis. Blood 2002; 100:3484-3488.

130. Meyer G, Marjanovic Z, Valcke J, et al. Comparison of low-molecularweight heparin and warfarin for the secondary prevention of venous thromboembolism in patients with cancer: A randomized controlled study. Arch Intern Med 2002;162:1729-1735.

131. Hull RD, Pineo GF, Brant RF, et al. Long-term low-molecular-weight heparin versus usual care in proximal-vein thrombosis patients with cancer. Am J Med 2006;119:1062-1072.

132. Schiff RL, Kahn SR, Shrier I, et al. Identifying orthopedic patients at high risk for venous thromboembolism despite thromboprophylaxis. Chest 2005; 128:3364-3371.

133. Hoppener MR, Ettema HB, Henny CP, Verheyen CC, Buller HR. Low incidence of deep vein thrombosis after knee arthroscopy without thromboprophylaxis: A prospective cohort study of 335 patients. Acta Orthop 2006;77:767-771.

134. Mantilla CB, Horlocker TT, Schroeder DR, Berry DJ, Brown DL. Risk factors for clinically relevant pulmonary embolism and deep venous thrombosis in patients undergoing primary hip or knee arthroplasty. Anesthesiology 2003;99:552-560; discussion 555A.

135. Nathan SS, Simmons KA, Lin PP, et al. Proximal deep vein thrombosis after hip replacement for oncologic indications. J Bone Joint Surg Am 2006;88:1066-1070.

136. Lassen MR, Bauer KA, Eriksson BI, Turpie AG. Postoperative fondaparinux versus preoperative enoxaparin for prevention of venous thromboembolism in elective hip-replacement surgery: A randomised double-blind comparison. Lancet 2002;359:1715-1720.

137. Turpie AG, Bauer KA, Eriksson BI, Lassen MR. Postoperative fondaparinux versus postoperative enoxaparin for prevention of venous thromboembolism after elective hip-replacement surgery: A randomised double-blind trial. Lancet 2002;359:1721-1726.

138. Turpie AG, Bauer KA, Eriksson BI, Lassen MR. Fondaparinux vs enoxaparin for the prevention of venous thromboembolism in major orthopedic surgery: A meta-analysis of 4 randomized double-blind studies. Arch Intern Med 2002;162:1833-1840.

139. Eriksson BI, Bauer KA, Lassen MR, Turpie AG. Fondaparinux compared with enoxaparin for the prevention of venous thromboembolism after hip-fracture surgery. N Engl J Med 2001;345:1298-1304.

140. Glotzbecker MP, Bono CM, Wood KB, Harris MB. Thromboembolic disease in spinal surgery: A systematic review. Spine (Phila Pa 1976) 2009;34:291-303.

141. Huang ME, Johns JS, White J, Sanford K. Venous thromboembolism in a rehabilitation setting after major lower-extremity amputation. Arch Phys Med Rehabil 2005;86:73-78. 
142. Zickler RW, Gahtan V, Matsumoto T, Kerstein MD. Deep venous thrombosis and pulmonary embolism in bilateral lower-extremity amputee patients. Arch Phys Med Rehabil 1999;80:509-511.

143. Chong DK, Panju A. Deep venous thrombosis as a cause of stump swelling in two lower extremity amputee patients. Arch Phys Med Rehabil 1993;74:1002-1003.

144. Knight MT, Dawson R. Effect of intermittent compression of the arms on deep venous thrombosis in the legs. Lancet 1976;2:1265-1268.

145. Killewich LA, Cahan MA, Hanna DJ, et al. The effect of external pneumatic compression on regional fibrinolysis in a prospective randomized trial. J Vasc Surg 2002;36:953-958.

146. Cahan MA, Hanna DJ, Wiley LA, Cox DK, Killewich LA. External pneumatic compression and fibrinolysis in abdominal surgery. J Vasc Surg 2000;32:537-543

147. Brandstater ME, Roth EJ, Siebens HC. Venous thromboembolism in stroke: Literature review and implications for clinical practice. Arch Phys Med Rehabil 992;73:S379-S391.

148. Skaf E, Stein PD, Beemath A, Sanchez J, Bustamante MA, Olson RE. Venous thromboembolism in patients with ischemic and hemorrhagic stroke. Am J Cardiol 2005;96:1731-1733.

149. Kamran SI, Downey D, Ruff RL. Pneumatic sequential compression reduces the risk of deep vein thrombosis in stroke patients. Neurology 1998;50:1683-1688.

150. Imberti $D$, Prisco D. Venous thromboembolism prophylaxis in medical patients: Future perspectives. Thromb Res 2005;116:365-375.

151. Davenport RJ, Dennis MS, Wellwood I, Warlow CP. Complications after acute stroke. Stroke 1996;27:415-420.

152. Aptaker RL, Roth EJ, Reichhardt G, Duerden ME, Levy CE. Serum albumin level as a predictor of geriatric stroke rehabilitation outcome. Arch Phys Med Rehabil 1994;75:80-84.

153. Kelly J, Rudd A, Lewis R, Hunt BJ. Venous thromboembolism after acute stroke. Stroke 2001;32:262-267.

154. Sandercock P, Counsell C, Stobbs SL. Low-molecular-weight heparins or heparinoids versus standard unfractionated heparin for acute ischaemic stroke. Cochrane Database Syst Rev 2005;(2):CD000119.

155. Harvey RL, Lovell LL, Belanger N, Roth EJ. The effectiveness of anticoagulant and antiplatelet agents in preventing venous thromboembolism during stroke rehabilitation: A historical cohort study. Arch Phys Med Rehabil 2004;85:1070-1075

156. Gubitz G, Sandercock P, Counsell C. Anticoagulants for acute ischaemic stroke. Cochrane Database Syst Rev 2004:(3):CD00002.

157. Chamorro A, Vila N, Saiz A, Alday M, Tolosa E. Early anticoagulation after large cerebral embolic infarction: A safety study. Neurology 1995:45:861-865

158. Gregory PC, Kuhlemeier KV. Prevalence of venous thromboembolism in acute hemorrhagic and thromboembolic stroke. Am J Phys Med Rehabil 2003:82:364-369.

159. Mazzone C, Chiodo Grandi F, Sandercock P, Miccio M, Salvi R. Physical methods for preventing deep vein thrombosis in stroke. Cochrane Database Syst Rev 2004;(4):CD001922

160. Kamphuisen PW, Agnelli G. What is the optimal pharmacological prophylaxis for the prevention of deep-vein thrombosis and pulmonary embolism in patients with acute ischemic stroke? Thromb Res 2007;119:265-274

161. Kearon CM, Kahn SR, Agnelli G, Goldhaber S, Raskob GE, Comerota AJ. Antithrombotic therapy for venous thromboembolic disease: American College of Chest Physicians Evidence-Based Clinical Practice Guidelines (8th Edition). Chest 2008;133:454S-545S.

162. Bath PM, Iddenden R, Bath FJ. Low-molecular-weight heparins and heparinoids in acute ischemic stroke: A meta-analysis of randomized controlled trials. Stroke 2000;31:1770-1778

163. Kamphuisen PW, Agnelli G, Sebastianelli M. Prevention of venous thromboembolism after acute ischemic stroke. J Thromb Haemost 2005;3:1187-1194.
164. Broderick J, Connolly S, Feldmann E, et al. Guidelines for the management of spontaneous intracerebral hemorrhage in adults: 2007 update: A guideline from the American Heart Association/American Stroke Association Stroke Council, High Blood Pressure Research Council, and the Quality of Care and Outcomes in Research Interdisciplinary Working Group. Circulation 2007;116:e391-413.

165. Iorio A, Agnelli G. Low-molecular-weight and unfractionated heparin for prevention of venous thromboembolism in neurosurgery: A metaanalysis. Arch Intern Med 2000;160:2327-2332.

166. Schulman S, Beyth RJ, Kearon C, Levine MN. Hemorrhagic complications of anticoagulant and thrombolytic treatment: American College of Chest Physicians Evidence-Based Clinical Practice Guidelines (8th Edition). Chest 2008;133:257S-298S.

167. Wilson RD, Murray PK. Cost-effectiveness of screening for deep vein thrombosis by ultrasound at admission to stroke rehabilitation. Arch Phys Med Rehabil 2005;86:1941-1948.

168. Reiff DA, Haricharan RN, Bullington NM, Griffin RL, McGwin GJr, Rue LW 3rd. Traumatic brain injury is associated with the development of deep vein thrombosis independent of pharmacological prophylaxis. J Trauma 2009;66:1436-1440.

169. Geerts WH, Code KI, Jay RM, Chen E, Szalai JP. A prospective study of venous thromboembolism after major trauma. N Engl J Med 1994:331:1601-1606.

170. Bratton SL, Chestnut RM, Ghajar J, et al. Guidelines for the management of severe traumatic brain injury. V. Deep vein thrombosis prophylaxis. J Neurotrauma 2007;24(Suppl 1):S32-S36.

171. Yablon SA, Rock WA, Ng WK, Nick TG, McGrath CM. Evidence for an acute-phase hypercoagulable state as a major risk factor for venous thromboembolic disease among rehabilitation admission with acquired brain injury. Am J Phys Med Rehabil 2000;79:204-205.

172. Carlile MC, Yablon SA, Mysiw WJ, Frol AB, Lo D, Diaz-Arrastia R. Deep venous thrombosis management following traumatic brain injury: A practice survey of the traumatic brain injury model systems. J Head Trauma Rehabil 2006:21:483-490

173. Hyers TM, Agnelli G, Hull RD, et al. Antithrombotic therapy for venous thromboembolic disease. Chest 2001;119(1 Suppl):176S193S.

174. Kim J, Gearhart MM, Zurick A, Zuccarello M, James L, Luchette FA. Preliminary report on the safety of heparin for deep venous thrombosis prophylaxis after severe head injury. J Trauma 2002;53:38-42; discussion 43.

175. Meythaler JM, Fisher WS, Rue LW, Johnson A, Davis L, Brunner RC. Screening for venous thromboembolism in traumatic brain injury: Limitations of D-dimer assay. Arch Phys Med Rehabil 2003;84:285290.

176. Yablon $S A$, Rock WA Jr, Nick TG, Sherer M, McGrath CM, Goodson KH. Deep vein thrombosis: Prevalence and risk factors in rehabilitation admissions with brain injury. Neurology 2004;63:485-491

177. Prisco D, Grifoni E. The role of D-dimer testing in patients with suspected venous thromboembolism. Semin Thromb Hemost 2009; 35:50-59

178. Cifu DX, Kaelin DL, Wall BE. Deep venous thrombosis: Incidence on admission to a brain injury rehabilitation program. Arch Phys Med Rehabil 1996;77:1182-1185.

179. Meythaler JM, DeVivo MJ, Hayne JB. Cost-effectiveness of routine screening for proximal deep venous thrombosis in acquired brain injury patients admitted to rehabilitation. Arch Phys Med Rehabil 1996;77:1-5

180. Page RB, Spott MA, Krishnamurthy S, Taleghani $C$, Chinchilli VM. Head injury and pulmonary embolism: A retrospective report based on the Pennsylvania Trauma Outcomes study. Neurosurgery 2004; 54:143-148; discussion 148-149.

181. Marras LC, Geerts WH, Perry JR. The risk of venous thromboembolism is increased throughout the course of malignant glioma: An evidence-based review. Cancer 2000;89:640-646. 
182. Chan AT, Atiemo A, Diran LK, et al. Venous thromboembolism occurs frequently in patients undergoing brain tumor surgery despite prophylaxis. J Thromb Thrombolysis 1999;8:139-142.

183. Walsh DC, Kakkar AK. Thromboembolism in brain tumors. Curr Opin Pulm Med 2001;7:326-331.

184. Ruff RL, Posner JB. Incidence and treatment of peripheral venous thrombosis in patients with glioma. Ann Neurol 1983;13:334-336.

185. Wen DY, Hall WA. Complications of subcutaneous low-dose heparin therapy in neurosurgical patients. Surg Neurol 1998;50:521-525.

186. Macdonald RL, Amidei C, Lin G, et al. Safety of perioperative subcutaneous heparin for prophylaxis of venous thromboembolism in patients undergoing craniotomy. Neurosurgery 1999;45:245-251; discussion 251-242

187. Constantini S, Kanner A, Friedman A, et al. Safety of perioperative minidose heparin in patients undergoing brain tumor surgery: A prospective, randomized, double-blind study. J Neurosurg 2001;94: 918-921.

188. Agnelli G, Piovella F, Buoncristiani P, et al. Enoxaparin plus compression stockings compared with compression stockings alone in the prevention of venous thromboembolism after elective neurosurgery. N Engl J Med 1998;339:80-85.

189. Dickinson LD, Miller LD, Patel CP, Gupta SK. Enoxaparin increases the incidence of postoperative intracranial hemorrhage when initiated preoperatively for deep venous thrombosis prophylaxis in patients with brain tumors. Neurosurgery 1998;43:1074-1081.

190. Cage TA, Lamborn KR, Ware ML, et al. Adjuvant enoxaparin therapy may decrease the incidence of postoperative thrombotic events though does not increase the incidence of postoperative intracranial hemorrhage in patients with meningiomas. J Neurooncol 2009;93: 151-156.

191. Tetri S, Hakala J, Juvela S, et al. Safety of low-dose subcutaneous enoxaparin for the prevention of venous thromboembolism after primary intracerebral haemorrhage. Thromb Res 2008;123:206-212.

192. Raabe $A$, Gerlach $R$, Zimmermann $M$, Seifert $V$. The risk of haemorrhage associated with early postoperative heparin administration after intracranial surgery. Acta Neurochir (Wien) 2001;143:1-7.

193. Goldhaber SZ, Dunn K, Gerhard-Herman M, Park JK, Black PM. Low rate of venous thromboembolism after craniotomy for brain tumor using multimodality prophylaxis. Chest 2002;122:1933-1937.

194. Sharpe RP, Gupta R, Gracias VH, et al. Incidence and natural history of below-knee deep venous thrombosis in high-risk trauma patients. J Trauma 2002;53:1048-1052.

195. Kiser TS, Stefans VA. Pulmonary embolism in rehabilitation patients: Relation to time before return to physical therapy after diagnosis of deep vein thrombosis. Arch Phys Med Rehabil 1997;78:942-945.

196. Kahn SR, Shrier I, Kearon C. Physical activity in patients with deep venous thrombosis: A systematic review. Thromb Res 2008;122:763-773.

197. Aldrich D, Hunt DP. When can the patient with deep venous thrombosis begin to ambulate? Phys Ther 2004:84:268-273.
198. Ciccone CD. Clinical question: Does ambulation immediately following an episode of deep vein thrombosis increase the risk of pulmonary embolism? Phys Ther 2002;82:84-88.

199. Aschwanden $\mathrm{M}$, Labs $\mathrm{KH}$, Engel $\mathrm{H}$, et al. Acute deep vein thrombosis: Early mobilization does not increase the frequency of pulmonary embolism. Thromb Haemost 2001;85:42-46.

200. Partsch H. Ambulation and compression after deep vein thrombosis: Dispelling myths. Semin Vasc Surg 2005;18:148-152.

201. Partsch $H$, Blattler W. Compression and walking versus bed rest in the treatment of proximal deep venous thrombosis with low molecular weight heparin. J Vasc Surg 2000;32:861-869.

202. Kroll HR, Odderson IR, Allen FH. Deep vein thrombi associated with the use of plastic ankle-foot orthoses. Arch Phys Med Rehabil 1998; 79:576-578.

203. Hara $Y$. Deep venous thrombosis in stroke patients during rehabilitation phase. Keio J Med 2008;57:196-204

204. Segal JB, Streiff MB, Hofmann LV, Thornton K, Bass EB. Management of venous thromboembolism: A systematic review for a practice guideline. Ann Intern Med 2007;146:211-222.

205. Linkins LA, Choi PT, Douketis JD. Clinical impact of bleeding in patients taking oral anticoagulant therapy for venous thromboembolism: A meta-analysis. Ann Intern Med 2003;139:893-900.

206. van Dongen CJ, Vink R, Hutten BA, Buller HR, Prins MH. The incidence of recurrent venous thromboembolism after treatment with vitamin $\mathrm{K}$ antagonists in relation to time since first event: A metaanalysis. Arch Intern Med 2003;163:1285-1293.

207. Agnelli G, Prandoni P, Santamaria MG, et al. Three months versus one year of oral anticoagulant therapy for idiopathic deep venous thrombosis. Warfarin Optimal Duration Italian Trial Investigators. N Engl J Med 2001;345:165-169.

208. Palareti $G$, Cosmi $B$, Legnani $C$, et al. D-dimer testing to determine the duration of anticoagulation therapy. N Engl J Med 2006;355:17801789.

209. Cosmi B, Legnani C, Cini M, Guazzaloca G, Palareti G. D-dimer levels in combination with residual venous obstruction and the risk of recurrence after anticoagulation withdrawal for a first idiopathic deep vein thrombosis. Thromb Haemost 2005;94:969-974.

210. Ridker PM, Goldhaber SZ, Danielson E, et al. Long-term, low-intensity warfarin therapy for the prevention of recurrent venous thromboembolism. N Engl J Med 2003;348:1425-1434.

211. Kearon C, Ginsberg JS, Kovacs MJ, et al. Comparison of low-intensity warfarin therapy with conventional-intensity warfarin therapy for long-term prevention of recurrent venous thromboembolism. N Engl J Med 2003;349:631-639.

This CME activity is designated for 1.0 AMA PRA Category 1 Credit ${ }^{\mathrm{TM}}$ and can be completed online at me.aapmr.org. Log on to www.me.aapmr.org, go to Lifelong Learning (CME) and select Journal-based CME from the drop down menu. This activity is FREE to AAPMER members and $\$ 25$ for non-members. 